\begin{tabular}{|c|l|}
\hline Title & A nalyzing tourists' satisfaction : A multivariate ordered probit approach \\
\hline Author(s) & Hasegawa, Hikaru \\
\hline Citation & $\begin{array}{l}\text { Tourism Management, 31/1), 86-97 } \\
\text { https://doi.org/10.1016/.tourman.2009.01.008 }\end{array}$ \\
\hline Issue Date & 2010-02 \\
\hline Doc URL & http://hdl.handle.net/2115/42486 \\
\hline Type & article (author version) \\
\hline File Information & TM31-1_86-97.pdf \\
\hline
\end{tabular}

Instructions for use 


\title{
Analyzing Tourists' Satisfaction: A Multivariate Ordered Probit Approach
}

Hikaru Hasegawa

Graduate School of Economics and Business Administration

Hokkaido University

Kita 9, Nishi 7, Kita-ku, Sapporo 060-0809, Japan

Tel.: +81117063179

E-mail address: hasegawa@econ.hokudai.ac.jp

\begin{abstract}
This article considers a Bayesian estimation of the multivariate ordered probit model using a Markov chain Monte Carlo (MCMC) method. The method is applied to unit record data on the satisfaction experienced by tourists. The data were obtained from the Annual Report on the Survey of Tourists' Satisfaction 2002, conducted by the Department of Economic Affairs of the Hokkaido government. Furthermore, using the posterior results of the Bayesian analysis, indices of the relationship between the overall satisfaction derived from the trip and the satisfaction derived from specific aspects of the trip are constructed. The results revealed that the satisfaction derived from the scenery and meals has the largest influence on the overall satisfaction.

Keywords: Bayesian analysis, Gibbs sampling, Markov chain Monte Carlo (MCMC), Metropolis-Hastings (M-H) algorithm.
\end{abstract}

JEL Classification: C11, C35

\section{Aknowledgements}

The author appreciates the comments of four anonymous referees and Professor Chris Ryan (the editor of this journal), which improve the article greatly. This work was supported in part by a Grant-in-Aid for Scientific Research (No.19530177) from the JSPS. 


\section{Introduction}

In this article, we statistically analyze the satisfaction experienced by tourists who visited Hokkaido, an island in northern Japan (Figure 1). Several attempts are being made to conserve the natural environment in Hokkaido, which still remains untouched; for example, in July 2005 the Shiretoko Peninsula, which is situated in the northeast of Hokkaido, was designated as a world natural heritage site. According to the data obtained by the Hokkaido government, 6.35 million tourists visited Hokkaido in 2005. The tourism industry is one of the most important industries of Hokkaido's economy. In order to analyze tourist satisfaction, we use the unit records data from the Annual Report on the Survey of Tourists' Satisfaction 2002, conducted by the Department of Economic Affairs of the Hokkaido government. The data reveal the degree of tourist satisfaction on the basis of several questionnaire items.

Numerous studies have been devoted to analyzing tourist satisfaction; for example, Kozak (2001b), Yuksel and Yuksel (2001a,b), Bowen and Clarke (2002), and Ryan and Cessford (2003) review the research on tourist satisfaction. According to Yuksel and Yuksel (2001b, pp.82-83), there are three aspects of customer (tourist) satisfaction that are widely debated: the definition of customer satisfaction, the relationship between customer satisfaction and service quality, ${ }^{1}$ and the measurement of customer satisfaction. There are many approaches for measuring customer satisfaction, including the expectation-performance, importance-performance, disconfirmation, and performance-only approaches (Kozak, 2001b, pp.305-309). Studies on customer satisfaction often use a $C$-point scale to measure satisfaction, even if they employ different approaches. ${ }^{2}$ For instance, Tonge and Moore (2007) use a 5-point scale for measuring satisfaction and importance. Sandvik and Grønhaug (2007) use 5-, 10-, and 11-point scales for constructing several degrees of satisfaction and repurchase intention. In the literature on tourism, most of the studies concerning consumer satisfaction use discrete ordinal data, considering them to be continuous. For example, Tonge

\footnotetext{
${ }^{1}$ For the relationship between tourist satisfaction and service quality, see, for example, Tribe and Snaith (1998) and Ryan and Cessford (2003).

${ }^{2}$ In the questionnaire survey concerning customer satisfaction, the choices are often arranged by using a $C$-point scale.
} 
and Moore (2007, Table 5) calculated the sample means of satisfaction and importance measures and found that the gap between the two means was statistically significant. Kozak (2001a) and Yu and Goulden (2006) make the same use of ordinal data as do Tonge and Moore (2007). Many studies employ structural equation models, which include factor analysis, for analyzing tourist satisfaction (see, for example, Pizam et al., 1978, and more recent studies by Sirakaya et al., 2004; Thompson and Schofield, 2007; and Silvestre et al., 2008). Further, $\mathrm{Qu}$ and Ping (1999) consider a logistic model for estimating the likelihood of going on a cruise in Hong Kong and use tourist satisfaction data as explanatory variables. These analyses often use the values of ordinal data themselves. However, since the values of ordinal data only indicate the order of the degrees of satisfaction, these numerical values per se are meaningless; it would, however, be meaningful to examine the magnitude of the relation between the ordinal values. Therefore, an ordered probit model is useful for statistically analyzing the data of such ordinal choices. In the literature on tourist satisfaction, there is a rather small body of research that employs an ordered probit model. An exception is the study by Oliveira and Pereira (2008), which employs an ordered probit model to examine how the sociodemographic characteristics of tourists and the different aspects of the trip affect the tourists' evaluation of 30 different aspects of the destination. In general, a multivariate ordered probit model can be employed when the questionnaire contains two or more attributes.

From the frequentist viewpoint, an ordered probit model can be estimated by the maximum likelihood method (see, for example, Greene, 2003, Chapter 21). On the other hand, a Bayesian analysis by using the Markov chain Monte Carlo (MCMC) method has become popular for the estimation of the ordered probit model after Albert and Chib's (1993) seminal work, which utilizes latent variable representation. Although the latent variables are unknown, their full conditional distribution (FCD) follows a truncated normal distribution. This makes the estimation of the ordered probit model very tractable in the Bayesian analysis (see Albert and Chib, 1993). Further, Chen and Dey (2000), Rossi et al. (2001), and Kottas et al. (2005) apply the Bayesian multivariate ordered probit model for two or more questionnaire items. Since the latent variables in the multivariate ordered probit model are correlated, we must consider this 
correlation while estimating the model. However, it is necessary to impose restrictions on the parameters in order to identify them. A sufficient condition of this identification problem is that the covariance matrix of the latent variables is defined as a form of the correlation matrix. This makes the estimation of the model difficult. Chen and Dey (2000) successfully overcame this difficulty by using a joint reparameterization of the correlation matrix and cutoff points for the ordinal data.

The unit records data utilized in our study were obtained from the Annual Report on the Survey of Tourists' Satisfaction 2002. The data reveal the degrees of tourist satisfaction derived from several aspects of the trip, namely, the trip as a whole ("overall satisfaction"), "meals," "souvenir items," "accommodation," "service," "transportation facilities," "tourist facilities," and "scenic beauty." The data also contain information on tourist characteristics and the regions visited. The degree of satisfaction pertaining to each questionnaire item can be analyzed using a univariate ordered probit model. It is also important to examine the relationship between the degree of satisfaction derived from individual aspects of the trip. We investigate the relationship between the overall satisfaction and the degree of satisfaction from individual aspects of the trip on the basis of the estimation of the Bayesian multivariate ordered probit model. Using the posterior results of the Bayesian analysis, we also construct the indices of the relationship between the overall satisfaction and the satisfaction derived from the specific aspects of the trip.

The rest of the article are organized as follows. In Section 2, following Chen and Dey (2000), we examine the Bayesian multivariate ordered probit model. In Section 3, we propose two types of indices of the relationship between the overall satisfaction and the satisfaction derived from the specific aspects of the trip. Section 4 provides the empirical results of applying the multivariate ordered probit model to the unit records data obtained from the Annual Report on the Survey of Tourists' Satisfaction 2002. Further, we investigate the factors that improve tourist satisfaction. In Section 5, we provide concluding remarks and mention some extensions of our approach. 


\section{Bayesian Multivariate Ordered Probit Model}

In this section, following Chen and Dey (2000), we describe the Bayesian multivariate probit model. Let $y_{i j}$ denote the discrete ordinal responses of an individual $i$ to an item $j$, for $i=1, \cdots, n$ and $j=1, \cdots, m$; that is $y_{i j}=c$ for $c=1, \cdots, C$. For example, $y_{i j}=1$ denotes "strongly dissatisfied," $y_{i j}=2$ denotes "dissatisfied," and so on.

Further, let $z_{i j}$ denote a latent variable of an individual $i$ to an item $j$ such that

$$
y_{i j}=c \text { if } z_{i j} \in\left(\gamma_{j, c-1}, \gamma_{j c}\right], i=1, \cdots, n ; j=1, \cdots, m ; c=1, \cdots, C,
$$

where $\gamma_{j c}$ is the cutoff of the $j$ th ordinal response. The latent variable $z_{i j}$ is assumed to be determined by the linear model

$$
z_{i j}=\boldsymbol{x}_{i j}^{\prime} \boldsymbol{\beta}_{j}+u_{i j}, i=1, \cdots, n ; j=1, \cdots, m,
$$

where

$$
\boldsymbol{x}_{i j}=\left(\begin{array}{c}
x_{i j 1} \\
x_{i j 2} \\
\vdots \\
x_{i j k_{j}}
\end{array}\right), \boldsymbol{\beta}_{j}=\left(\begin{array}{c}
\beta_{j 1} \\
\beta_{j 2} \\
\vdots \\
\beta_{j k_{j}}
\end{array}\right), i=1, \cdots, n ; j=1, \cdots, m .
$$

Defining

$$
\begin{aligned}
& \boldsymbol{z}_{i}=\left(\begin{array}{c}
z_{i 1} \\
z_{i 2} \\
\vdots \\
z_{i m}
\end{array}\right), \boldsymbol{X}_{i}=\left(\begin{array}{cccc}
\boldsymbol{x}_{i 1}^{\prime} & & & \mathbf{O} \\
& \boldsymbol{x}_{i 2}^{\prime} & & \\
& & \ddots & \\
\mathbf{O} & & & \boldsymbol{x}_{i m}^{\prime}
\end{array}\right) \\
& \boldsymbol{\beta}=\left(\begin{array}{c}
\boldsymbol{\beta}_{1} \\
\boldsymbol{\beta}_{2} \\
\vdots \\
\boldsymbol{\beta}_{m}
\end{array}\right), \boldsymbol{u}_{i}=\left(\begin{array}{c}
u_{i 1} \\
u_{i 2} \\
\vdots \\
u_{i m}
\end{array}\right), i=1, \cdots, n,
\end{aligned}
$$

the linear model for the latent variables is rewritten as

$$
\boldsymbol{z}_{i}=\boldsymbol{X}_{i} \boldsymbol{\beta}+\boldsymbol{u}_{i}, i=1, \cdots, n \text {. }
$$


We now assume that $\boldsymbol{u}_{i} \sim \mathrm{N}(\mathbf{0}, \boldsymbol{\Sigma})$; that is,

$$
\boldsymbol{z}_{i} \sim \mathrm{N}\left(\boldsymbol{X}_{i} \boldsymbol{\beta}, \boldsymbol{\Sigma}\right), i=1, \cdots, n
$$

A sufficient condition for the identification of parameters is that the $m \times m$ positive definite covariance matrix is in the correlation form, as mentioned by Chib and Greenberg (1998, p.348). This makes the estimation of the model difficult. Chen and Dey (2000) propose the joint reparameterization of the correlation matrix and cutoff points for avoiding the direct treatment of the correlation matrix. After implementing the reparameterization proposed by Chen and Dey (2000), we can consider $\boldsymbol{\Sigma}$ as a typical covariance matrix. Further, the cutoffs can be specified as

$$
\begin{aligned}
-\infty & =\gamma_{j 0}<\gamma_{j 1}=0<\gamma_{j 2}<\cdots<\gamma_{j(C-2)}<\gamma_{j(C-1)}=1<\gamma_{j C}=\infty \\
& j=1, \cdots, m .
\end{aligned}
$$

In order to complete the Bayesian model, we introduce the prior distributions of the parameters $p(\boldsymbol{\beta}, \boldsymbol{\Sigma}, \boldsymbol{\gamma})$. According to Bayes' theorem, the joint posterior distribution can be written as

$$
\begin{aligned}
& p(\boldsymbol{\beta}, \boldsymbol{\Sigma}, \boldsymbol{\gamma}, \boldsymbol{z} \mid \boldsymbol{y}) \propto p(\boldsymbol{\beta}, \boldsymbol{\Sigma}, \gamma, \boldsymbol{z}) p(\boldsymbol{y} \mid \boldsymbol{\beta}, \boldsymbol{\Sigma}, \gamma, \boldsymbol{z}) \\
& \quad=p(\boldsymbol{\beta}, \boldsymbol{\Sigma}, \gamma) p(\boldsymbol{z} \mid \boldsymbol{\beta}, \boldsymbol{\Sigma}, \gamma) p(\boldsymbol{y} \mid \boldsymbol{\beta}, \boldsymbol{\Sigma}, \gamma, \boldsymbol{z}) \\
& \quad=p(\boldsymbol{\beta}, \boldsymbol{\Sigma}, \gamma)\left\{\prod_{i=1}^{n} p\left(\boldsymbol{z}_{i} \mid \boldsymbol{\beta}, \boldsymbol{\Sigma}, \gamma\right) p\left(\boldsymbol{y}_{i} \mid \boldsymbol{\beta}, \boldsymbol{\Sigma}, \gamma, \boldsymbol{z}_{i}\right)\right\},
\end{aligned}
$$

where

$$
\begin{gathered}
\gamma_{j}=\left(\begin{array}{c}
\gamma_{j 2} \\
\gamma_{j 3} \\
\vdots \\
\gamma_{j(C-2)}
\end{array}\right), j=1, \cdots, m, \gamma=\left(\begin{array}{c}
\gamma_{1} \\
\gamma_{2} \\
\vdots \\
\gamma_{m}
\end{array}\right) \\
\boldsymbol{y}_{i}=\left(\begin{array}{c}
y_{i 1} \\
y_{i 2} \\
\vdots \\
y_{i m}
\end{array}\right), i=1, \cdots, n, \boldsymbol{y}=\left(\begin{array}{c}
\boldsymbol{y}_{1} \\
\boldsymbol{y}_{2} \\
\vdots \\
\boldsymbol{y}_{n}
\end{array}\right), \boldsymbol{z}=\left(\begin{array}{c}
\boldsymbol{z}_{1} \\
\boldsymbol{z}_{2} \\
\vdots \\
\boldsymbol{z}_{n}
\end{array}\right) .
\end{gathered}
$$


Defining

$$
\begin{aligned}
& \mathcal{G}_{i j}=\left(\gamma_{j(c-1)}, \gamma_{j c}\right] \text { if } y_{i j}=c, i=1, \cdots, n ; j=1, \cdots, m \\
& \mathcal{G}_{i}=\mathcal{G}_{i 1} \times \cdots \times \mathcal{G}_{i m}, i=1, \cdots, n,
\end{aligned}
$$

we have

$$
p\left(\boldsymbol{y}_{i} \mid \boldsymbol{\beta}, \boldsymbol{\Sigma}, \boldsymbol{\gamma}, \boldsymbol{z}_{i}\right)=1_{\left(\boldsymbol{z}_{i} \in \mathcal{G}_{i}\right)}, i=1, \cdots, n
$$

where $1_{(\cdot)}$ is an indicator function. We now specify the prior distributions as follows:

$$
p(\boldsymbol{\beta}, \boldsymbol{\Sigma}, \boldsymbol{\gamma})=p(\boldsymbol{\beta}) p\left(\boldsymbol{\Sigma}^{-1}\right) p(\boldsymbol{\gamma})=\left\{\prod_{j=1}^{m} p\left(\boldsymbol{\beta}_{j}\right)\right\} p\left(\boldsymbol{\Sigma}^{-1}\right)\left\{\prod_{j=1}^{m} p\left(\boldsymbol{\gamma}_{j}\right)\right\}
$$

and

$$
\left\{\begin{array}{l}
\boldsymbol{\beta}_{j} \sim \mathrm{N}\left(\boldsymbol{\beta}_{j 0}, \boldsymbol{B}_{j 0}\right), j=1, \cdots, m \\
\boldsymbol{\Sigma}^{-1} \sim \mathrm{W}\left(\nu_{0}, \boldsymbol{Q}_{0}^{-1}\right) \\
p\left(\boldsymbol{\gamma}_{j}\right) \propto 1 \text { for } 0<\gamma_{j 2}<\cdots<\gamma_{j(C-2)}<1, j=1, \cdots, m,
\end{array}\right.
$$

where $\mathrm{W}(a, \boldsymbol{A})$ denotes a Wishart distribution with degrees of freedom $a$ and a scale matrix $\boldsymbol{A}$. Thus, the posterior distribution (4) can be written as

$$
p(\boldsymbol{\beta}, \boldsymbol{\Sigma}, \boldsymbol{\gamma}, \boldsymbol{z} \mid \boldsymbol{y}) \propto\left\{\prod_{j=1}^{m} p\left(\boldsymbol{\beta}_{j}\right)\right\} p\left(\boldsymbol{\Sigma}^{-1}\right) \prod_{i=1}^{n}\left[1_{\left(\boldsymbol{z}_{i} \in \mathcal{G}_{i}\right)} p\left(\boldsymbol{z}_{i} \mid \boldsymbol{\beta}, \boldsymbol{\Sigma}, \boldsymbol{\gamma}\right)\right] .
$$

Using the MCMC method, we can easily generate the parameters from the posterior distribution expressed in (6). The details of the sampling algorithms are provided in the Appendix.

\section{Indices of the Relationship between the Over- all Satisfaction and the Satisfaction Derived from Individual Aspects of the Trip}

One of the merits of the Bayesian approach is that we can estimate the latent variables $\boldsymbol{z}$. Using the latent variables $\boldsymbol{z}$, we construct the indices of the relationship between the overall satisfaction and the satisfaction derived from specific aspects of the trip. 
By dividing the vector of latent variables as $\boldsymbol{z}_{i}=\left(z_{i 1}, \boldsymbol{z}_{i(-1)}^{\prime}\right)^{\prime}$, where $\boldsymbol{z}_{i 1}$ is the latent variable for the overall satisfaction and $\boldsymbol{z}_{i(-1)}$ is the vector of the latent variables representing the satisfaction derived from the specific aspects of the trip, we consider the following regression model:

$$
z_{i 1}=\alpha_{1}+\boldsymbol{z}_{i(-1)}^{\prime} \boldsymbol{\alpha}_{2}+v_{i}, i=1, \cdots, n \text {. }
$$

This regression model can be written as

$$
\boldsymbol{z}_{(1)}=\left(\boldsymbol{\iota}, \boldsymbol{Z}_{(-1)}\right) \boldsymbol{\alpha}+\boldsymbol{v}
$$

where

$$
\boldsymbol{z}_{(1)}=\left(\begin{array}{c}
z_{11} \\
z_{21} \\
\vdots \\
z_{n 1}
\end{array}\right), \boldsymbol{Z}_{(-1)}=\left(\begin{array}{c}
\boldsymbol{z}_{1(-1)}^{\prime} \\
\boldsymbol{z}_{2(-1)}^{\prime} \\
\vdots \\
\boldsymbol{z}_{n(-1)}^{\prime}
\end{array}\right), \iota=\left(\begin{array}{c}
1 \\
1 \\
\vdots \\
1
\end{array}\right), \boldsymbol{\alpha}=\left(\begin{array}{c}
\alpha_{1} \\
\boldsymbol{\alpha}_{2}
\end{array}\right), \boldsymbol{v}=\left(\begin{array}{c}
v_{1} \\
v_{2} \\
\vdots \\
v_{n}
\end{array}\right)
$$

Let $\hat{\boldsymbol{\alpha}}=\left(\hat{\alpha}_{1}, \hat{\boldsymbol{\alpha}}_{2}^{\prime}\right)^{\prime}$ denote the ordinary least squares (OLS) estimates of $\boldsymbol{\alpha}$ in (7). We define the OLS estimate $\hat{\boldsymbol{\alpha}}_{2}$ as the first type of index of the relationship between the overall satisfaction and the satisfaction from the specific aspects of the trip. Thus, $\hat{\boldsymbol{\alpha}}_{2}$ is derived as

$$
\hat{\boldsymbol{\alpha}}_{2}=\left(\boldsymbol{Z}_{(-1)}^{\prime} \boldsymbol{M}^{0} \boldsymbol{Z}_{(-1)}\right)^{-1} \boldsymbol{Z}_{(-1)}^{\prime} \boldsymbol{M}^{0} \boldsymbol{z}_{(1)}
$$

where $\boldsymbol{M}^{0}=\boldsymbol{I}-\frac{1}{n} \boldsymbol{\iota} \boldsymbol{\iota}^{\prime}$. By defining $\boldsymbol{S}_{z}=\left(\begin{array}{cc}s_{11} & \boldsymbol{s}_{(-1)}^{\prime} \\ \boldsymbol{s}_{(-1)} & \boldsymbol{S}_{(-1)}\end{array}\right)$ as the sample covariance matrix of $\boldsymbol{z}$ - that is, $\boldsymbol{S}_{z}=\frac{1}{n} \boldsymbol{Z}^{\prime} \boldsymbol{M}^{0} \boldsymbol{Z}$, where $\boldsymbol{Z}=\left(\boldsymbol{z}_{(1)}, \boldsymbol{Z}_{(-1)}\right)$, we have $\hat{\boldsymbol{\alpha}}_{2}=\boldsymbol{S}_{(-1)}^{-1} \boldsymbol{s}_{(-1)}{ }^{3}$ As against the second type of index proposed below, the first type of index is not controlled by the explanatory variables $\boldsymbol{X}$.

The second type of index of the relationship between the overall satisfaction and the satisfaction derived from the specific aspects of the trip is constructed from the covariance matrix $\boldsymbol{\Sigma}$. The joint distribution of $\boldsymbol{z}_{i}=\left(z_{i 1}, \boldsymbol{z}_{i(-1)}^{\prime}\right)^{\prime}$ can be written as

$$
p\left(\boldsymbol{z}_{i} \mid \boldsymbol{X}_{i}, \boldsymbol{\beta}, \boldsymbol{\Sigma}, \boldsymbol{\gamma}\right)=p\left(z_{i 1} \mid \boldsymbol{z}_{i(-1)}, \boldsymbol{X}_{i}, \boldsymbol{\beta}, \boldsymbol{\Sigma}, \boldsymbol{\gamma}\right) p\left(\boldsymbol{z}_{i(-1)} \mid \boldsymbol{X}_{i}, \boldsymbol{\beta}, \boldsymbol{\Sigma}, \boldsymbol{\gamma}\right)
$$

\footnotetext{
${ }^{3}$ See also Rossi et al. (2001).
} 
Since $\boldsymbol{z}_{i} \mid \boldsymbol{X}_{i}, \boldsymbol{\beta}, \boldsymbol{\Sigma}, \boldsymbol{\gamma} \sim \mathrm{N}\left(\boldsymbol{X}_{i} \boldsymbol{\beta}, \boldsymbol{\Sigma}\right)$, we have

$$
z_{i 1} \mid \boldsymbol{z}_{i(-1)}, \boldsymbol{X}_{i}, \boldsymbol{\beta}, \boldsymbol{\Sigma}, \boldsymbol{\gamma} \sim \mathrm{N}\left(\tilde{\mu}_{i 1}, \tilde{\sigma}_{i 1}^{2}\right), i=1, \cdots, n
$$

where

$$
\begin{aligned}
& \tilde{\mu}_{i 1}=\boldsymbol{x}_{i 1}^{\prime} \boldsymbol{\beta}_{1}+\boldsymbol{\sigma}_{(-1)}^{\prime} \boldsymbol{\Sigma}_{(-1)}^{-1}\left(\boldsymbol{z}_{i(-1)}-\boldsymbol{X}_{i(-1)} \boldsymbol{\beta}_{(-1)}\right) \\
& \tilde{\sigma}_{i 1}^{2}=\sigma_{11}-\boldsymbol{\sigma}_{(-1)}^{\prime} \boldsymbol{\Sigma}_{(-1)}^{-1} \boldsymbol{\sigma}_{(-1)} \\
& \boldsymbol{\beta}=\left(\begin{array}{c}
\boldsymbol{\beta}_{1} \\
\boldsymbol{\beta}_{(-1)}
\end{array}\right), \boldsymbol{\Sigma}=\left(\begin{array}{cc}
\sigma_{11} & \boldsymbol{\sigma}_{(-1)}^{\prime} \\
\boldsymbol{\sigma}_{(-1)} & \boldsymbol{\Sigma}_{(-1)}
\end{array}\right) .
\end{aligned}
$$

Thus, we have

$$
z_{i 1}-\boldsymbol{x}_{i 1}^{\prime} \boldsymbol{\beta}_{1} \mid \boldsymbol{z}_{i(-1)}, \boldsymbol{X}_{i}, \boldsymbol{\beta}, \boldsymbol{\Sigma}, \boldsymbol{\gamma} \sim \mathrm{N}\left(\tilde{\mu}_{i 1}^{*}, \tilde{\sigma}_{i 1}^{2}\right), i=1, \cdots, n
$$

where

$$
\tilde{\mu}_{i 1}^{*}=\boldsymbol{\sigma}_{(-1)}^{\prime} \boldsymbol{\Sigma}_{(-1)}^{-1}\left(\boldsymbol{z}_{i(-1)}-\boldsymbol{X}_{i(-1)} \boldsymbol{\beta}_{(-1)}\right) .
$$

From the equation pertaining to the conditional mean $\tilde{\mu}_{i 1}^{*}$, we use $\boldsymbol{\delta}=\boldsymbol{\Sigma}_{(-1)}^{-1} \boldsymbol{\sigma}_{(-1)}$ as the index of measuring the relationship between the overall satisfaction and the satisfaction derived from the specific aspects of the trip. Since (8) is based on the residuals $z_{i 1}-\boldsymbol{x}_{i 1}^{\prime} \boldsymbol{\beta}_{1}$ and $\boldsymbol{z}_{i(-1)}-\boldsymbol{X}_{i(-1)} \boldsymbol{\beta}_{(-1)}$, the second type of index, $\boldsymbol{\delta}$, can be considered as the relationship between the overall satisfaction and the satisfaction derived from individual aspects of the trip, given the explanatory variables $\boldsymbol{X}$.

\section{Empirical Analysis of Tourism in Hokkaido Prefecture}

\subsection{Data}

We use the survey data from the Annual Report on the Survey of Tourists' Satisfaction 2002, conducted by the Department of Economic Affairs of the Hokkaido government. ${ }^{4}$ The Hokkaido government conducted the survey by using the interview method. Kau and Lim (2005, p.235) and Clerides and Pashourtidou

${ }^{4}$ The report was published in 2003. Further, the year 2002 denotes a fiscal year, that is, April 2002 to March 2003. 
(2007, p.58) employ a similar method of data collection, using personal interviews conducted by means of a questionnaire. Tourists were interviewed just prior to departure from Hokkaido. The interviews were conducted at airports, ferry terminals, and on express trains with sleeping berths, in September and October 2002 and February 2003. The respondents were asked about their overall satisfaction from the trip as well as the satisfaction derived from specific aspects of the trip. The data also contain information on tourist characteristics and the regions visited.

The data comprise 3,679 unit records. We eliminated the unit records that contained identical responses to all items on satisfaction and those where items had not been answered. We also eliminated the unit records pertaining to daytrippers and foreign visitors since such records numbered less than 10 . We finally obtained a total of 3,398 unit records for this estimation. Tables 1 and 2 present the definitions of the variables that are used in the analysis. Table 1 provides the frequencies and percentages of the unit records under each category. Table 2 provides the frequencies and percentages of the choices (corresponding to the degree of satisfaction) regarding the items pertaining to each aspect of the trip.

In our analysis, the dependent variables are the degrees of satisfaction derived from the trip: "overall satisfaction" (satall), "satisfaction from meals" (satfood), "satisfaction from souvenir items" (satsouv), "satisfaction from accommodation" (sataccom), "satisfaction from service" (satserv), "satisfaction from transportation facilities" (sattran), "satisfaction from tourist facilities" (satequip), and "satisfaction from scenic beauty" (satview). The regressors are the dummy variables of "tourist's sex" (fem), "age" (age), "place of residence" (reg), "type of package tour" (pack), "number of persons accompanying the tourist" (tour), "duration of stay (itinerary)" (day), "number of visits to Hokkaido" (time), "transportation facilities" (tran), "type of accommodation" (accom), and "region visited" (route). The seven regions visited and the number of tourists who visited these regions are provided in Table 1. Figure 2 depicts the locations of the seven regions visited in Hokkaido Prefecture. In addition, a tourist who satisfied the following conditions was selected as a "reference tourist": "male" (fem $=0)$, in the "twenties" (age2 =1), resided in the "Kanto region" ( $r$ geg = 1), had joined a "free package tour" $($ pack3 = 1), 
had toured in a "small group" (less than six persons) (tour4 = 1), had visited Hokkaido for "two nights" (day2 = 1), was a "first-time" visitor (time1 = 1), and had rented a car using a "rent-a-car" service ( $\operatorname{tran5}=1$ ).

\subsection{Posterior Results}

We assume the following linear models for the latent variable of the degree of satisfaction derived from each aspect of the trip:

$$
\begin{aligned}
& z_{\text {satall }}=\beta_{10}+\beta_{11} \text { fem }+\boldsymbol{\beta}_{12}^{\prime} \text { age }+\boldsymbol{\beta}_{13}^{\prime} \text { reg }+\boldsymbol{\beta}_{14}^{\prime} \text { pack }+\boldsymbol{\beta}_{15}^{\prime} \text { tour } \\
& +\boldsymbol{\beta}_{16}^{\prime} \text { day }+\boldsymbol{\beta}_{17}^{\prime} \text { time }+\boldsymbol{\beta}_{18}^{\prime} \text { tran }+\boldsymbol{\beta}_{19}^{\prime} \text { accom }+\boldsymbol{\beta}_{1,10}^{\prime} \text { route } \\
& z_{\text {satfood }}=\beta_{20}+\beta_{21} \text { fem }+\boldsymbol{\beta}_{22}^{\prime} \text { age }+\boldsymbol{\beta}_{23}^{\prime} \text { reg }+\boldsymbol{\beta}_{24}^{\prime} \text { pack }+\boldsymbol{\beta}_{25}^{\prime} \text { tour } \\
& +\boldsymbol{\beta}_{26}^{\prime} \text { day }+\boldsymbol{\beta}_{27}^{\prime} \text { time }+\boldsymbol{\beta}_{28}^{\prime} \text { accom }+\boldsymbol{\beta}_{29}^{\prime} \text { route } \\
& z_{\text {satsouv }}=\beta_{30}+\beta_{31} \text { fem }+\boldsymbol{\beta}_{32}^{\prime} \text { age }+\boldsymbol{\beta}_{33}^{\prime} \text { reg }+\boldsymbol{\beta}_{34}^{\prime} \text { pack }+\boldsymbol{\beta}_{35}^{\prime} \text { tour } \\
& +\boldsymbol{\beta}_{36}^{\prime} \text { day }+\boldsymbol{\beta}_{37}^{\prime} \text { time }+\boldsymbol{\beta}_{38}^{\prime} \text { route } \\
& z_{\text {sataccom }}=\beta_{40}+\beta_{41} \text { fem }+\boldsymbol{\beta}_{42}^{\prime} \text { age }+\boldsymbol{\beta}_{43}^{\prime} \text { reg }+\boldsymbol{\beta}_{44}^{\prime} \text { pack }+\boldsymbol{\beta}_{45}^{\prime} \text { tour } \\
& +\boldsymbol{\beta}_{46}^{\prime} \text { day }+\boldsymbol{\beta}_{47}^{\prime} \text { time }+\boldsymbol{\beta}_{48}^{\prime} \text { accom }+\boldsymbol{\beta}_{49}^{\prime} \text { route } \\
& z_{\text {satserv }}=\beta_{50}+\beta_{51} \text { fem }+\boldsymbol{\beta}_{52}^{\prime} \text { age }+\boldsymbol{\beta}_{53}^{\prime} \text { reg }+\boldsymbol{\beta}_{54}^{\prime} \text { pack }+\boldsymbol{\beta}_{55}^{\prime} \text { tour } \\
& +\boldsymbol{\beta}_{56}^{\prime} \text { day }+\boldsymbol{\beta}_{57}^{\prime} \text { time }+\boldsymbol{\beta}_{58}^{\prime} \operatorname{tran}+\boldsymbol{\beta}_{59}^{\prime} \text { accom }+\boldsymbol{\beta}_{5,10}^{\prime} \text { route } \\
& z_{\text {sattran }}=\beta_{60}+\beta_{61} \text { fem }+\boldsymbol{\beta}_{62}^{\prime} \text { age }+\boldsymbol{\beta}_{63}^{\prime} \text { reg }+\boldsymbol{\beta}_{64}^{\prime} \text { pack }+\boldsymbol{\beta}_{65}^{\prime} \text { tour } \\
& +\boldsymbol{\beta}_{66}^{\prime} \text { day }+\boldsymbol{\beta}_{67}^{\prime} \text { time }+\boldsymbol{\beta}_{68}^{\prime} \operatorname{tran}+\boldsymbol{\beta}_{69}^{\prime} \text { route } \\
& z_{\text {satequip }}=\beta_{70}+\beta_{71} \text { fem }+\boldsymbol{\beta}_{72}^{\prime} \text { age }+\boldsymbol{\beta}_{73}^{\prime} \text { reg }+\boldsymbol{\beta}_{74}^{\prime} \text { pack }+\boldsymbol{\beta}_{75}^{\prime} \text { tour } \\
& +\boldsymbol{\beta}_{76}^{\prime} \text { day }+\boldsymbol{\beta}_{77}^{\prime} \text { time }+\boldsymbol{\beta}_{78}^{\prime} \text { tran }+\boldsymbol{\beta}_{79}^{\prime} \text { accom }+\boldsymbol{\beta}_{7,10}^{\prime} \text { route } \\
& z_{\text {satview }}=\beta_{80}+\beta_{81} \text { fem }+\boldsymbol{\beta}_{82}^{\prime} \text { age }+\boldsymbol{\beta}_{83}^{\prime} \text { reg }+\boldsymbol{\beta}_{84}^{\prime} \text { pack }+\boldsymbol{\beta}_{85}^{\prime} \text { tour } \\
& +\boldsymbol{\beta}_{86}^{\prime} \text { day }+\boldsymbol{\beta}_{87}^{\prime} \text { time }+\boldsymbol{\beta}_{88}^{\prime} \text { route, }
\end{aligned}
$$

where age, reg, pack, tour, day, time, tran, accom, and route are the vectors of the dummy variables of age, place of residence, type of package tour, number of persons accompanying the tourist, itinerary, number of visits to Hokkaido, transportation facilities, type of accommodation, and region visited, respectively. We use the variables fem, age, reg, pack, tour, day, time, and route as regressors in all the linear equations, and tran and accom are used as regressors of the degrees of satisfaction to which the regressors are related. Since $C=5$, 
the cutoff points that should be estimated are $\gamma_{j c}(j=1, \cdots, 8 ; c=2,3)$. We use Ox 4.02 for the estimation of the multivariate ordered probit model (see Doornik, 2006) . We set the prior distributions as follows:

$$
\begin{aligned}
& \boldsymbol{\beta}_{j} \sim \mathrm{N}(\mathbf{0}, 100 \times \boldsymbol{I}), j=1, \cdots, 8, \boldsymbol{\Sigma}^{-1} \sim \mathrm{W}(10,1000 \times \boldsymbol{I}) \\
& p\left(\boldsymbol{\gamma}_{j}\right) \propto 1, \text { for } 0<\gamma_{j 2}<\gamma_{j 3}<1, j=1, \cdots, 8
\end{aligned}
$$

The MCMC simulation was run for 30,000 iterations, and the first 10,000 samples were discarded as a burn-in period. Hence, we use 20,000 samples to calculate the posterior means and standard deviations of the parameters. Table 3 provides the posterior results of $\boldsymbol{\beta}$. Tables 4 and 5 provide the posterior results of $\boldsymbol{\Sigma}$ and $\boldsymbol{\gamma}$. From Tables 4 and 5 , we can observe that the $95 \%$ credible intervals do not include zero for all elements of $\boldsymbol{\Sigma}$ and $\boldsymbol{\gamma}$.

The following points can be observed from the posterior results in Table 3.

- The $95 \%$ credible interval for the intercept in each equation does not include zero. This implies that the intercepts of the reference tourists are "significant." Here, the term significant is used if the $95 \%$ credible interval for a parameter does not include zero (see Koop, 2003, p.124).

- The degree of satisfaction experienced by females is considerably higher than that experienced by males in most equations, with the exception of satfood (meals), sataccom (accommodation), and sattran (transportation facilities).

- The degree of satisfaction experienced by tourists of age3, age4, and age5 are significantly lower than that experienced by tourists of age2 (reference tourists), with the exception of a few insignificant coefficients.

- With regard to meals and souvenir items, the degree of satisfaction experienced by the tourists who joined a group package tour (pack1) is lower than that experienced by the reference tourists who did not join the package tour (pack3). Further, with regard to meals, the degree of satisfaction experienced by the tourists who joined a free package tour (pack2) is lower than that experienced by the reference tourists (pack3).

- With regard to the number of persons accompanying the tourist, the degree of satisfaction experienced by the tourists who joined in tour1, tour2, 
tour3, and tour5 is lower than that experienced by the reference tourists (tour4) for some categories of satisfaction. On the contrary, the degree of satisfaction experienced by the tourists who were on their honeymoon (tour6) is higher than that experienced by the reference tourists.

- With regard to the itinerary, the question concerning transportation facilities (sattran) revealed that the tourists who stayed for more than six nights (day7) experienced a lower degree of satisfaction than did the reference tourists who stayed for two nights (day2).

- With regard to the overall satisfaction derived from the trip (satall), the degree of satisfaction decreased with an increase in the number of visits to Hokkaido.

- With regard to the transportation facilities, tourists using motorcycles (tran6) experienced a higher degree of satisfaction from the trip as a whole (satall) and tourist facilities (satequip) than did the reference tourists who used rent-a-car services (tran5). Furthermore, the tourists who used chartered buses $(\operatorname{tran} 1)$, railroads $(\operatorname{tran} 2)$, and taxies $(\operatorname{tran} 7)$ experienced a higher degree of satisfaction from service (satserv) than did the reference tourists.

- The tourists who stayed at youth hostels (accom8) experienced high degrees of satisfaction from accommodation facilities (sataccom) and from service (satserv).

- The tourists who visited the Kushiro and Nemuro regions (route7) experienced a high degree of satisfaction with regard to the trip as a whole (satall), meals (satfood), tourist facilities (satequip), and scenic beauty (satview). In these regions, seafood is abundantly available. Furthermore, with regard to the scenic beauty (satview), those who visited the southern region (route1) indicated a high degree of satisfaction. The southern area (route1) and the Kushiro and Nemuro regions (route7) are known for their historical landmarks and rich natural beauty (e.g., the Shiretoko Peninsula), respectively.

Tables 6 (a) and (b) present the posterior results for the two types of indices 
of the relationship between the overall satisfaction and the satisfaction derived from the specific aspects of the trip. These tables provide the actual figures of the indices and their percentages, respectively. Table 6 (b) also presents the order in which the degree of satisfaction from the individual aspects of the trip influence the overall satisfaction. For each index, the satisfaction derived from the scenic beauty and that derived from meals have the largest and second largest influence, respectively, on the overall satisfaction. The visited regions for which the satisfaction from the scenic beauty is high are the southern region and the Kushiro and Nemuro regions; ${ }^{5}$ these regions are particularly noteworthy for their historical landmarks or rich natural beauty. Furthermore, tourists visiting the Kushiro and Nemuro regions also indicated a high degree of satisfaction from meals. In these regions, seafood is abundantly available. ${ }^{6}$ These observations are consistent with the posterior results of the multivariate ordered probit model provided in Table 3 . On the other hand, the satisfaction from the transportation facilities has the smallest influence on the overall satisfaction. Although the magnitudes of the two types of indices are slightly different, the results are similar irrespective of which index is used.

\section{Concluding Remarks}

In this article, we analyzed the degree of satisfaction experienced by tourists who visited Hokkaido, using the survey data from the Annual Report on the Survey of Tourists' Satisfaction 2002, conducted by the Department of Economic Affairs of the Hokkaido government. The survey collected data pertaining to the degrees of satisfaction from the trip as a whole (overall satisfaction), meals, souvenir items, accommodation, service, transportation facilities, tourist facilities, and scenic beauty. Therefore, we were able to consider the effects of the degree of satisfaction with respect to each category on the degree of the overall satisfaction from the trip to Hokkaido. For this analysis, we estimated a Bayesian multivariate ordered probit model describing the satisfaction of tourists visiting Hokkaido. Furthermore, we provided two types of indices of the relationship be-

\footnotetext{
${ }^{5}$ See route1 (the southern region) and route6 (the Kushiro and Nemuro regions) in the equation of satview in Table 3.

${ }^{6}$ See route6 (the Kushiro and Nemuro regions) in the equation of satfood in Table 3.
} 
tween the overall satisfaction derived from the trip and the satisfaction derived from the specific aspects of the trip. The results revealed that the satisfaction derived from the scenery and meals has the largest influence on the overall satisfaction. In addition to the relationships among several types of satisfaction, we examined the relationship between each satisfaction and the explanatory variables, which are the attributes of the trips, by estimating the multivariate ordered probit model. These results provide suggestions on the tourism policy for the development of the tourism industry.

In order to develop the tourism industry, it is necessary to create incentives for the tourists so that they continue to visit Hokkaido. The results of this study clarified that one such incentive is the development of a new type of package travel that values high-quality scenic beauty and meals. Since untouched nature and historical landmarks are valuable resources contributing to the quality of scenic beauty, it is important to conserve them. Furthermore, it is necessary to develop new food products, making use of the abundant seafood and farm products in Hokkaido. The maintenance of the transport network between tourist spots is also important to improve the degree of tourist satisfaction.

Rossi et al. (2001) consider scale usage heterogeneity and show that it can induce a substantial bias in the correlation between the overall satisfaction derived from a product and the satisfaction derived from specific product attributes. In the future, we will incorporate scale usage heterogeneity into the multivariate ordered probit model for resolving any such bias in the analysis concerning scale usage heterogeneity. Further, in this article, we employed information about tourists who visited Hokkaido as dummy variables. However, the spatial relationships among the degrees of tourist satisfaction from visits to various regions cannot be adequately captured by using dummy variables. Therefore, in future research, we intend to apply the methods of spatial econometrics and/or spatial statistics to the multivariate ordered probit model in order to resolve this issue. 


\section{A Sampling algorithms}

\section{A.1 Sampling of $\beta$}

The full conditional distribution (FCD) of $\boldsymbol{\beta}_{j}$ is

$$
\begin{gathered}
p\left(\boldsymbol{\beta}_{j} \mid \cdots\right) \propto \exp \left[-\frac{1}{2}\left\{\left(\boldsymbol{\beta}_{j}-\boldsymbol{\beta}_{j 0}\right)^{\prime} \boldsymbol{B}_{j 0}^{-1}\left(\boldsymbol{\beta}_{j}-\boldsymbol{\beta}_{j 0}\right)\right.\right. \\
\left.\left.+\sum_{i=1}^{n}\left(\boldsymbol{z}_{i}-\boldsymbol{X}_{i} \boldsymbol{\beta}\right)^{\prime} \boldsymbol{\Sigma}^{-1}\left(\boldsymbol{z}_{i}-\boldsymbol{X}_{i} \boldsymbol{\beta}\right)\right\}\right]
\end{gathered}
$$

where ' $\mid$...' denotes conditioning on the values of all other parameters and data. Further, for the sake of convenience of expression, we replace the $j$ th factor as the first factor as follows:

$$
\begin{aligned}
& \boldsymbol{z}_{i}=\left(\begin{array}{c}
z_{i j} \\
\boldsymbol{z}_{i(-j)}
\end{array}\right), \boldsymbol{X}_{i}=\left(\begin{array}{cc}
\boldsymbol{x}_{i j}^{\prime} & \mathbf{0}^{\prime} \\
\mathbf{0} & \boldsymbol{X}_{i(-j)}
\end{array}\right), \boldsymbol{\beta}=\left(\begin{array}{c}
\boldsymbol{\beta}_{j} \\
\boldsymbol{\beta}_{(-j)}
\end{array}\right) \\
& \boldsymbol{\Sigma}^{-1}=\left(\begin{array}{cc}
\sigma^{j j} & \boldsymbol{\sigma}^{(-j) \prime} \\
\boldsymbol{\sigma}^{(-j)} & \boldsymbol{\Sigma}^{(-j)}
\end{array}\right) .
\end{aligned}
$$

Since

$$
\begin{aligned}
\left(\boldsymbol{z}_{i}-\right. & \left.\boldsymbol{X}_{i} \boldsymbol{\beta}\right)^{\prime} \boldsymbol{\Sigma}^{-1}\left(\boldsymbol{z}_{i}-\boldsymbol{X}_{i} \boldsymbol{\beta}\right) \\
& =\left(\begin{array}{c}
z_{i j}-\boldsymbol{x}_{i j}^{\prime} \boldsymbol{\beta}_{j} \\
\boldsymbol{z}_{i(-j)}-\boldsymbol{X}_{i(-j)} \boldsymbol{\beta}_{(-j)}
\end{array}\right)\left(\begin{array}{cc}
\sigma^{j j} & \boldsymbol{\sigma}^{(-j) \prime} \\
\boldsymbol{\sigma}^{(-j)} & \boldsymbol{\Sigma}^{(-j)}
\end{array}\right)\left(\begin{array}{c}
z_{i j}-\boldsymbol{x}_{i j}^{\prime} \boldsymbol{\beta}_{j} \\
\boldsymbol{z}_{i(-j)}-\boldsymbol{X}_{i(-j)} \boldsymbol{\beta}_{(-j)}
\end{array}\right) \\
& =\sigma^{j j} \boldsymbol{\beta}_{j}^{\prime} \boldsymbol{x}_{i j} \boldsymbol{x}_{i j}^{\prime} \boldsymbol{\beta}_{j}-2 \boldsymbol{\beta}_{j}^{\prime}\left[\sigma^{j j} \boldsymbol{x}_{i j} z_{i j}+\boldsymbol{x}_{i j} \boldsymbol{\sigma}^{(-j) \prime}\left(\boldsymbol{z}_{i(-j)}-\boldsymbol{X}_{i(-j)} \boldsymbol{\beta}_{(-j)}\right)\right]+\cdots
\end{aligned}
$$

we obtain

$$
\begin{aligned}
& \left(\boldsymbol{\beta}_{j}-\boldsymbol{\beta}_{j 0}\right)^{\prime} \boldsymbol{B}_{j 0}^{-1}\left(\boldsymbol{\beta}_{j}-\boldsymbol{\beta}_{j 0}\right)+\sum_{i=1}^{n}\left(\boldsymbol{z}_{i}-\boldsymbol{X}_{i} \boldsymbol{\beta}\right)^{\prime} \boldsymbol{\Sigma}^{-1}\left(\boldsymbol{z}_{i}-\boldsymbol{X}_{i} \boldsymbol{\beta}\right) \\
& =\boldsymbol{\beta}_{j}^{\prime}\left(\boldsymbol{B}_{j 0}^{-1}+\sigma^{j j} \sum_{i=1}^{n} \boldsymbol{x}_{i j} \boldsymbol{x}_{i j}^{\prime}\right) \boldsymbol{\beta}_{j} \\
& \quad-2 \boldsymbol{\beta}_{j}^{\prime}\left[\boldsymbol{B}_{j 0}^{-1} \boldsymbol{\beta}_{j 0}+\sigma^{j j} \sum_{i=1}^{n} \boldsymbol{x}_{i j} z_{i j}+\sum_{i=1}^{n} \boldsymbol{x}_{i j} \boldsymbol{\sigma}^{(-j) \prime}\left(\boldsymbol{z}_{i(-j)}-\boldsymbol{X}_{i(-j)} \boldsymbol{\beta}_{(-j)}\right)\right]+\cdots .
\end{aligned}
$$

Therefore, we have

$$
\boldsymbol{\beta}_{j} \mid \cdots \sim \mathrm{N}\left(\tilde{\boldsymbol{\beta}}_{j}, \tilde{\boldsymbol{B}}_{j}\right), j=1, \cdots, m
$$


where

$$
\begin{aligned}
& \tilde{\boldsymbol{B}}_{j}=\left(\boldsymbol{B}_{j 0}^{-1}+\sigma^{j j} \sum_{i=1}^{n} \boldsymbol{x}_{i j} \boldsymbol{x}_{i j}^{\prime}\right)^{-1} \\
& \tilde{\boldsymbol{\beta}}_{j}=\tilde{\boldsymbol{B}}_{j}\left[\boldsymbol{B}_{j 0}^{-1} \boldsymbol{\beta}_{j 0}+\sigma^{j j} \sum_{i=1}^{n} \boldsymbol{x}_{i j} z_{i j}+\sum_{i=1}^{n} \boldsymbol{x}_{i j} \boldsymbol{\sigma}^{(-j) \prime}\left(\boldsymbol{z}_{i(-j)}-\boldsymbol{X}_{i(-j)} \boldsymbol{\beta}_{(-j)}\right)\right] .
\end{aligned}
$$

Applying Gibbs sampling to (9), we can generate $\boldsymbol{\beta}_{j}$.

\section{A.2 Sampling of $\Sigma^{-1}$}

Since the FCD of $\boldsymbol{\Sigma}^{-1}$ is

$$
\begin{aligned}
& p\left(\boldsymbol{\Sigma}^{-1} \mid \cdots\right) \propto\left|\boldsymbol{\Sigma}^{-1}\right|^{-\frac{1}{2}\left(\nu_{0}+n-m-1\right)} \\
& \quad \times \operatorname{etr}\left[-\frac{1}{2}\left\{\boldsymbol{Q}_{0}+\sum_{i=1}^{n}\left(\boldsymbol{z}_{i}-\boldsymbol{X}_{i} \boldsymbol{\beta}\right)\left(\boldsymbol{z}_{i}-\boldsymbol{X}_{i} \boldsymbol{\beta}\right)^{\prime}\right\} \boldsymbol{\Sigma}^{-1}\right],
\end{aligned}
$$

we have

$$
\boldsymbol{\Sigma}^{-1} \mid \cdots \sim \mathrm{W}\left(\tilde{\nu}, \tilde{\boldsymbol{Q}}^{-1}\right)
$$

where

$$
\tilde{\nu}=\nu_{0}+n, \tilde{\boldsymbol{Q}}=\boldsymbol{Q}_{0}+\sum_{i=1}^{n}\left(\boldsymbol{z}_{i}-\boldsymbol{X}_{i} \boldsymbol{\beta}\right)\left(\boldsymbol{z}_{i}-\boldsymbol{X}_{i} \boldsymbol{\beta}\right)^{\prime} .
$$

Applying Gibbs sampling to (10), we can generate $\boldsymbol{\Sigma}^{-1}$.

\section{A.3 Sampling of $z$ and $\gamma$}

Let $\boldsymbol{z}_{(j)}=\left(\begin{array}{llll}z_{1 j} & z_{2 j} & \cdots & z_{n j}\end{array}\right)^{\prime}$ denote the vector of the $j$ th element $z_{i j}$ from $\boldsymbol{z}_{i}(i=1, \cdots, n)$. Further, let $\boldsymbol{z}_{(-j)}$ denote the vector obtained by removing $\boldsymbol{z}_{(j)}$ from $\boldsymbol{z}$, and let $\boldsymbol{z}_{i(-j)}$ denote the vector of removing $z_{i j}$ from $\boldsymbol{z}_{i}$. We generate $\boldsymbol{\gamma}_{j}$ and $\boldsymbol{z}_{(j)}$ from the joint conditional distribution $p\left(\boldsymbol{\gamma}_{j}, \boldsymbol{z}_{(j)} \mid \boldsymbol{\beta}, \boldsymbol{\Sigma}, \boldsymbol{z}_{(-j)}, \boldsymbol{y}\right)(j=$ $1, \cdots, m)$. The joint conditional distribution $p\left(\gamma_{j}, \boldsymbol{z}_{(j)} \mid \boldsymbol{\beta}, \boldsymbol{\Sigma}, \boldsymbol{z}_{(-j)}, \boldsymbol{y}\right)$ can be written as

$$
\begin{aligned}
& p\left(\boldsymbol{\gamma}_{j}, \boldsymbol{z}_{(j)} \mid \boldsymbol{\beta}, \boldsymbol{\Sigma}, \boldsymbol{z}_{(-j)}, \boldsymbol{y}\right)=p\left(\boldsymbol{\gamma}_{j} \mid \boldsymbol{\beta}, \boldsymbol{\Sigma}, \boldsymbol{z}_{(-j)}, \boldsymbol{y}\right) p\left(\boldsymbol{z}_{(j)} \mid \boldsymbol{\gamma}_{j}, \boldsymbol{\beta}, \boldsymbol{\Sigma}, \boldsymbol{z}_{(-j)}, \boldsymbol{y}\right), \\
& \quad j=1, \cdots, m .
\end{aligned}
$$


Similar to the sampling of $\boldsymbol{\beta}_{j}$, for the sake of convenience of expression, we replace the $j$ th factor as the first factor as follows:

$$
\begin{aligned}
& \boldsymbol{z}_{i}=\left(\begin{array}{c}
z_{i j} \\
\boldsymbol{z}_{i(-j)}
\end{array}\right), \boldsymbol{X}_{i}=\left(\begin{array}{cc}
\boldsymbol{x}_{i j}^{\prime} & \mathbf{0}^{\prime} \\
\mathbf{0} & \boldsymbol{X}_{i(-j)}
\end{array}\right), \boldsymbol{\beta}=\left(\begin{array}{c}
\boldsymbol{\beta}_{j} \\
\boldsymbol{\beta}_{(-j)}
\end{array}\right) \\
& \boldsymbol{\Sigma}=\left(\begin{array}{cc}
\sigma_{j j} & \boldsymbol{\sigma}_{(-j)}^{\prime} \\
\boldsymbol{\sigma}_{(-j)} & \boldsymbol{\Sigma}_{(-j)}
\end{array}\right) .
\end{aligned}
$$

Since $\boldsymbol{z}_{i} \mid \boldsymbol{\beta}, \boldsymbol{\Sigma}, \boldsymbol{\gamma} \sim \mathrm{N}\left(\boldsymbol{X}_{i} \boldsymbol{\beta}, \boldsymbol{\Sigma}\right)$, from the property of the multivariate normal distribution we have

$$
z_{i j} \mid \boldsymbol{\gamma}_{j}, \boldsymbol{\beta}, \boldsymbol{\Sigma}, \boldsymbol{z}_{(-j)}, \boldsymbol{y} \sim \mathrm{N}\left(\tilde{\mu}_{i j}, \tilde{\sigma}_{i j}^{2}\right) 1_{\left(z_{i j} \in \mathcal{G}_{i j}\right)}, i=1, \cdots, n ; j=1, \cdots, m
$$

where

$$
\begin{aligned}
& \tilde{\mu}_{i j}=\boldsymbol{x}_{i j}^{\prime} \boldsymbol{\beta}_{j}+\boldsymbol{\sigma}_{(-j)}^{\prime} \boldsymbol{\Sigma}_{(-j)}^{-1}\left(\boldsymbol{z}_{i(-j)}-\boldsymbol{X}_{i(-j)} \boldsymbol{\beta}_{(-j)}\right) \\
& \tilde{\sigma}_{i j}^{2}=\sigma_{j j}-\boldsymbol{\sigma}_{(-j)}^{\prime} \boldsymbol{\Sigma}_{(-j)}^{-1} \boldsymbol{\sigma}_{(-j)} .
\end{aligned}
$$

Since given $\boldsymbol{\gamma}_{j}, \boldsymbol{\beta}, \boldsymbol{\Sigma}, z_{1 j}, z_{2 j}, \cdots, z_{n j}$ are independent, we have

$$
\begin{aligned}
& p\left(\gamma_{j} \mid \boldsymbol{\beta}, \boldsymbol{\Sigma}, \boldsymbol{z}_{(-j)}, \boldsymbol{y}\right) \propto \prod_{i: y_{i j}=2}\left[\Phi\left(\frac{\gamma_{j 2}-\tilde{\mu}_{i j}}{\tilde{\sigma}_{i j}}\right)-\Phi\left(-\frac{\tilde{\mu}_{i j}}{\tilde{\sigma}_{i j}}\right)\right] \\
& \times \prod_{i: y_{i j}=3}\left[\Phi\left(\frac{\gamma_{j 3}-\tilde{\mu}_{i j}}{\tilde{\sigma}_{i j}}\right)-\Phi\left(\frac{\gamma_{j 2}-\tilde{\mu}_{i j}}{\tilde{\sigma}_{i j}}\right)\right] \\
& \times \cdots \times \prod_{i: y_{i j}=C-1}\left[\Phi\left(\frac{1-\tilde{\mu}_{i j}}{\tilde{\sigma}_{i j}}\right)-\Phi\left(\frac{\gamma_{j(C-2)}-\tilde{\mu}_{i j}}{\tilde{\sigma}_{i j}}\right)\right],
\end{aligned}
$$

where $\Phi(\cdot)$ is the distribution function of the standard normal distribution. Chen and Dey (2000) propose the following Metropolis-Hastings (M-H) algorithm for generating $\gamma_{j}$. First, we put

$$
\gamma_{j c}=\frac{\gamma_{j(c-1)}+\exp \left(\zeta_{j c}\right)}{1+\exp \left(\zeta_{j c}\right)}, c=2, \cdots, C-2
$$

and $\boldsymbol{\zeta}_{j}=\left(\begin{array}{lll}\zeta_{j 2} & \cdots & \zeta_{j(C-2)}\end{array}\right)^{\prime}$. The conditional distribution of $\boldsymbol{\zeta}_{j}$ is

$$
p\left(\boldsymbol{\zeta}_{j} \mid \boldsymbol{\beta}, \boldsymbol{\Sigma}, \boldsymbol{z}_{(-j)}, \boldsymbol{y}\right) \propto p\left(\boldsymbol{\gamma}_{j} \mid \boldsymbol{\beta}, \boldsymbol{\Sigma}, \boldsymbol{z}_{(-j)}, \boldsymbol{y}\right) \prod_{c=2}^{C-2} \frac{\left(1-\gamma_{j(c-1)}\right) \exp \left(\zeta_{j c}\right)}{\left(1+\exp \left(\zeta_{j c}\right)\right)^{2}}
$$


where $p\left(\boldsymbol{\gamma}_{j} \mid \boldsymbol{\beta}, \boldsymbol{\Sigma}, \boldsymbol{z}_{(-j)}, \boldsymbol{y}\right)$ is given in (12). Instead of generating $\boldsymbol{\gamma}_{j}$ from (12) directly, we generate $\boldsymbol{\zeta}_{j}$ from (14) and obtain $\boldsymbol{\gamma}_{j}$ by using (13).

We use $\mathrm{N}\left(\hat{\boldsymbol{\zeta}}_{j}, \hat{\boldsymbol{\Sigma}}_{\boldsymbol{\zeta}_{j}}\right)$ as a proposal distribution for generating $\boldsymbol{\zeta}_{j}$, where $\hat{\boldsymbol{\zeta}}_{j}$ is the mode of (14),

$$
\hat{\boldsymbol{\Sigma}}_{\boldsymbol{\zeta}_{j}}=\tau\left\{\left[-\frac{\partial^{2} \log p\left(\boldsymbol{\zeta}_{j} \mid \boldsymbol{\beta}, \boldsymbol{\Sigma}, \boldsymbol{z}_{(-j)}, \boldsymbol{y}\right)}{\partial \boldsymbol{\zeta}_{j} \partial \boldsymbol{\zeta}_{j}^{\prime}}\right]_{\boldsymbol{\zeta}_{j}=\hat{\boldsymbol{\zeta}}_{j}}\right\}^{-1}
$$

and $\tau$ is a tuning parameter. The M-H algorithm for generating $\boldsymbol{\zeta}_{j}$ is as follows:

1. Let $\boldsymbol{\zeta}_{j}^{(t)}$ denote the value of $\boldsymbol{\zeta}_{j}$ at the $t$ th iteration.

2. At the $(t+1)$ th iteration, sample $\boldsymbol{\zeta}_{j}^{*}$ from $\mathrm{N}\left(\hat{\boldsymbol{\zeta}}_{j}, \hat{\boldsymbol{\Sigma}}_{\boldsymbol{\zeta}_{j}}\right)$.

3. The transition probability from $\boldsymbol{\zeta}_{j}^{(t)}$ to $\boldsymbol{\zeta}_{j}^{*}$ is

$$
\alpha=\min \left\{\frac{p\left(\boldsymbol{\zeta}_{j}^{*} \mid \boldsymbol{\beta}, \boldsymbol{\Sigma}, \boldsymbol{z}_{(-j)}, \boldsymbol{y}\right) \exp \left[-\frac{1}{2}\left(\boldsymbol{\zeta}_{j}^{(t)}-\hat{\boldsymbol{\zeta}}_{j}\right)^{\prime} \hat{\boldsymbol{\Sigma}}_{\boldsymbol{\zeta}_{j}}^{-1}\left(\boldsymbol{\zeta}_{j}^{(t)}-\hat{\boldsymbol{\zeta}}_{j}\right)\right]}{p\left(\boldsymbol{\zeta}_{j}^{(t)} \mid \boldsymbol{\beta}, \boldsymbol{\Sigma}, \boldsymbol{z}_{(-j)}, \boldsymbol{y}\right) \exp \left[-\frac{1}{2}\left(\boldsymbol{\zeta}_{j}^{*}-\hat{\boldsymbol{\zeta}}_{j}\right)^{\prime} \hat{\boldsymbol{\Sigma}}_{\boldsymbol{\zeta}_{j}}^{-1}\left(\boldsymbol{\zeta}_{j}^{*}-\hat{\boldsymbol{\zeta}}_{j}\right)\right]}, 1\right\} .
$$

4. Generate $u \sim \mathrm{U}(0,1)$, the uniform distribution on $(0,1)$, and take

$$
\boldsymbol{\zeta}_{j}^{(t+1)}= \begin{cases}\boldsymbol{\zeta}_{j}^{*} & \text { if } u<\alpha \\ \boldsymbol{\zeta}_{j}^{(t)} & \text { otherwise }\end{cases}
$$

\section{References}

Albert, J. H. \& Chib, S. (1993). Bayesian analysis of binary and polychotomous response data. Journal of the American Statistical Association 88, 669-679.

Bowen, D. \& Clarke, J. (2002). Reflections on tourist satisfaction research: Past, present and future. Journal of Vacation Marketing 8, 297-308.

Chen, M.-H. \& Dey, D.K. (2000). Bayesian analysis for correlated ordinal data models. In Dey, D. K., Ghosh, S. K. \& Mallick, B. K. eds., Generalized Linear Models: A Bayesian Perspective, New York: Marcel Dekker, 133-157.

Chib, S. \& Greenberg, E. (1998). Analysis of multivariate probit models. Biometrika 85, 347-361.

Clerides, S. \& Pashourtidou, N. (2007). Tourism in Cyprus: Recent trends and lessons from the tourist satisfaction survey. Cyprus Economic Policy Review 1, 51-72. 
Department of Economic Affairs of Hokkaido Government (2003). Annual Report on Survey of Tourists Satisfaction 2002 (in Japanese). (Available from http://www.pref.hokkaido.lg.jp/kz/kkd/260-dougai-doutai-tyousa/dogaiityosa.htm).

Doornik, J.A. (2006). An Object-oriented Matrix Programming Language: $\mathrm{Ox}^{T M} 4$, London: Timberlake Consultants Ltd.

Greene, W.H. (2003). Econometric Analysis 5th ed., Upper Saddle River: Prentice Hall.

Kau, A.K. and Lim, P.S. (2005). Clustering of Chinese tourists to Singapore: An analysis of their motivations, values and satisfaction. International Journal of Tourism Research 7, 231-248.

Koop, G. (2003). Bayesian Econometrics, Chichester: Wiley.

Kottas, A., Müller, P. \& Quintana, F. (2005). Nonparametric Bayesian modeling for multivariate ordinal data. Journal of Computational and Graphical Statistics 14, 610-625.

Kozak, M. (2001a). Comparative assessment of tourist satisfaction with destinations across two nationalities. Tourism Management 22, 391-401.

Kozak, M. (2001b). A critical review of approaches to measure satisfaction with tourist destinations. In Woodside, A.G., Mazanec, J.A., Brent Ritchie, J.R., Geoffrey I. and Crouch, G.I. eds. A critical review of approaches to measure satisfaction with tourist destinations, Volume 2, New York: CABI Publishing., 303-320.

Oliveira, P. \& Pereira, P.T. (2008). Who values what in a tourism destination? The case of Madeira island. Tourism Economics 14, 155-168.

Pizam, A., Y. Neumann, and A. Reichel (1978). Dimensions of tourist satisfaction with a destination area. Annals of Tourism Research 5, 314-322.

Qu, H. \& Ping, E.W.Y. (1999). A service performance model of Hong Kong cruise travelers' motivation factors and satisfaction. Tourism Management 20, $237-244$. 
Rossi, P.E., Gilula, Z. \& Allenby, G.M. (2001). Overcoming scale usage heterogeneity: A Bayesian hierarchical approach. Journal of the American Statistical Association 96, 20-31.

Ryan, C. \& G. Cessford (2003). Developing a visitor satisfaction monitoring methodology: Quality gaps, crowding and some results. Current Issues in Tourism 6, 457-507.

Sandvik, K. \& Grønhaug, K. (2007). How well does the firm know its customers? the moderating effect of market orientation in the hospitality industry. Tourism Economics 13, 5-23.

Silvestre, A.L., Santos, C.M. \& Ramalho, C. (2008). Satisfaction and behavioural intentions of cruise passengers visiting the Azores. Tourism Economics 14, 169-184.

Sirakaya, E., Petrick, J. \& Choi, H.-S. (2004). The role of mood on tourism product evaluations. Annals of Tourism Research 31, 517-539.

Tonge, J. \& Moore, S.A. (2007). Importance-satisfaction analysis for marinepark hinterlands: A western Australian case study. Tourism Management 28, 768-776.

Thompson, K. and P. Schofield (2007). An investigation of the relationship between public transport performance and destination satisfaction. Journal of Transport Geography 15, 136-144.

Tribe, J. and T. Snaith (1998). From SERVQUAL to HOLSAT: Holiday satisfaction in Varadero, Cuba. Tourism Management 19, 25-34.

Yu, L. \& Goulden, M. (2006). A comparative analysis of international tourists ' satisfaction in Mongolia. Tourism Management 27, 1331-1342.

Yuksel, A. \& Yuksel, F. (2001a). Measurement and management issues in customer satisfaction research: Review, critique and research agenda: Part one. Journal of Travel and Tourism Marketing 10, 47-80.

Yuksel, A. \& Yuksel, F. (2001b). Measurement and management issues in customer satisfaction research: Review, critique and research agenda: Part two. Journal of Travel and Tourism Marketing 10, 81-111. 
Table 1: Descriptive statistics of data

\begin{tabular}{|c|c|c|c|}
\hline & variable & frequency & $\%$ \\
\hline tourist's & female $(\mathrm{fem}=1)$ & 1,464 & 43.08 \\
\hline $\operatorname{sex}$ & male $(\mathrm{fem}=0)$ & 1,934 & 56.92 \\
\hline \multirow[t]{6}{*}{ age } & $\sim 19($ age $1=1)$ & 93 & 2.74 \\
\hline & $20 \sim 29($ age $2=1)$ & 760 & 22.37 \\
\hline & $30 \sim 39($ age $3=1)$ & 415 & 12.21 \\
\hline & $40 \sim 49($ age $4=1)$ & 360 & 10.59 \\
\hline & $50 \sim 59($ age $5=1)$ & 806 & 23.72 \\
\hline & $60 \sim($ age $6=1)$ & 964 & 28.37 \\
\hline \multirow{8}{*}{$\begin{array}{l}\text { place of } \\
\text { residence }\end{array}$} & Tohoku (reg1=1) & 203 & 5.97 \\
\hline & Kanto (reg2=1) & 1,210 & 35.61 \\
\hline & Hokuriku and Koshin-etsu (reg3=1) & 219 & 6.44 \\
\hline & Tokai $($ reg $4=1)$ & 452 & 13.30 \\
\hline & Kinki (reg5=1) & 602 & 17.72 \\
\hline & Chugoku (reg6=1) & 217 & 6.39 \\
\hline & Shikoku (reg7=1) & 103 & 3.03 \\
\hline & Kyushu and Okinawa (reg8=1) & 392 & 11.54 \\
\hline \multirow{3}{*}{$\begin{array}{l}\text { type of } \\
\text { package tour }\end{array}$} & inclusive package tour (pack1=1) & 1,355 & 39.88 \\
\hline & basic package tour (pack2=1) & 1,018 & 29.96 \\
\hline & not a package tour $($ pack3=1) & 1,025 & 30.16 \\
\hline \multirow{6}{*}{$\begin{array}{l}\text { number of } \\
\text { persons } \\
\text { accompanying } \\
\text { the tourist }\end{array}$} & group tour (more than 9 persons) (tour $1=1)$ & 981 & 28.87 \\
\hline & family tour (tour2=1) & 933 & 27.46 \\
\hline & small group tour $(6 \sim 9$ persons $)($ tour $3=1)$ & 345 & 10.15 \\
\hline & small group tour (less than 6 persons) (tour $4=1)$ & 742 & 21.84 \\
\hline & traveling alone $(\operatorname{tour} 5=1)$ & 329 & 9.68 \\
\hline & honeymoon (tour6=1) & 68 & 2.00 \\
\hline \multirow[t]{7}{*}{ itinerary } & 1 night $($ day1=1) & 267 & 7.86 \\
\hline & 2 nights $($ day $2=1)$ & 1,480 & 43.56 \\
\hline & 3 nights (day3=1) & 1,004 & 29.55 \\
\hline & 4 nights (day $4=1)$ & 336 & 9.89 \\
\hline & 5 nights (day5=1) & 96 & 2.83 \\
\hline & 6 nights (day6=1) & 59 & 1.74 \\
\hline & more than 6nights (day $7=1$ ) & 156 & 4.59 \\
\hline \multirow{3}{*}{$\begin{array}{l}\text { number of } \\
\text { visits to } \\
\text { Hokkaido }\end{array}$} & first-time (time1=1) & 892 & 26.25 \\
\hline & $2 \sim 4$ times $($ time $2=1)$ & 1,527 & 44.94 \\
\hline & more than 4 times (time $3=1)$ & 979 & 28.81 \\
\hline \multirow{10}{*}{$\begin{array}{l}\text { transportation } \\
\text { facilities }\end{array}$} & chartered bus $(\operatorname{tran} 1=1)$ & 1,430 & 42.08 \\
\hline & railroad $(\operatorname{tran} 2=1)$ & 616 & 18.13 \\
\hline & fixed route bus $(\operatorname{tran} 3=1)$ & 189 & 5.56 \\
\hline & private $\operatorname{car}(\operatorname{tran} 4=1)$ & 134 & 3.94 \\
\hline & rent-a-car $(\operatorname{tran} 5=1)$ & 667 & 19.63 \\
\hline & motorcycle $(\operatorname{tran} 6=1)$ & 37 & 1.09 \\
\hline & $\operatorname{taxi}(\operatorname{tran} 7=1)$ & 223 & 6.56 \\
\hline & bicycle $(\operatorname{tran} 8=1)$ & 14 & 0.41 \\
\hline & airplane $(\operatorname{tran} 9=1)$ & 25 & 0.74 \\
\hline & others $(\operatorname{tran} 10=1)$ & 63 & 1.85 \\
\hline
\end{tabular}


Table 1: Continued

\begin{tabular}{l|l|r}
\hline \multicolumn{1}{|c|}{ variable } & frequency \\
\hline type of & city type hotel (accom1=1) & 1,582 \\
accommodation & Japanese-style hotel (accom2=1) & 2,244 \\
& inexpensive hotel operated by a local government (accom3=1) & 61 \\
& guesthouse (accom4=1) & 115 \\
& accommodation managed by firms (accom5=1) & 21 \\
& friend's house (accom6=1) & 169 \\
& campsite (accom7=1) & 52 \\
& youth hostel (accom8=1) & 45 \\
& others (accom9=1) & 57 \\
\hline region visited & southern region (route1=1) & 601 \\
& central region (route2=1) & 3,044 \\
& south part of northern region (route3=1) & 1,008 \\
& north part of northern region (route4=1) & 561 \\
& Tokachi region (route5=1) & 868 \\
& Okhotsk region (route6=1) & 723 \\
\hline
\end{tabular}

Table 2 (a): Satisfaction for each questionnaire (frequency)

\begin{tabular}{l|ccccc}
\hline Question & Very & & & & Very \\
& Dissatisfied & Dissatisfied & Neutral & Satisfied & Satisfied \\
& 1 & 2 & 3 & 4 & 5 \\
\hline satfood & 57 & 206 & 806 & 1,082 & 1,247 \\
satsouv & 12 & 111 & 1,109 & 1,122 & 1,044 \\
sataccom & 47 & 136 & 1,045 & 1,042 & 1,128 \\
satserv & 21 & 92 & 1,302 & 1,053 & 930 \\
sattran & 82 & 138 & 1,612 & 866 & 700 \\
satequip & 31 & 102 & 1,503 & 979 & 783 \\
satview & 15 & 53 & 583 & 859 & 1,888 \\
satall & 17 & 39 & 571 & 1,192 & 1,579 \\
\hline
\end{tabular}

Table 2 (b): Satisfaction for each questionnaire (\%)

\begin{tabular}{l|ccccc}
\hline Question & Very & & & & Very \\
& Dissatisfied & Dissatisfied & Neutral & Satisfied & Satisfied \\
& 1 & 2 & 3 & 4 & 5 \\
\hline satfood & 1.68 & 6.06 & 23.72 & 31.84 & 36.70 \\
satsouv & 0.35 & 3.27 & 32.64 & 33.02 & 30.72 \\
sataccom & 1.38 & 4.00 & 30.75 & 30.67 & 33.20 \\
satserv & 0.62 & 2.71 & 38.32 & 30.99 & 27.37 \\
sattran & 2.41 & 4.06 & 47.44 & 25.49 & 20.60 \\
satequip & 0.91 & 3.00 & 44.23 & 28.81 & 23.04 \\
satview & 0.44 & 1.56 & 17.16 & 25.28 & 55.56 \\
satall & 0.50 & 1.15 & 16.80 & 35.08 & 46.47 \\
\hline
\end{tabular}


Tables 3: The posterior results of $\beta^{a}$

\begin{tabular}{|c|c|c|c|c|c|c|}
\hline & \multicolumn{3}{|c|}{ satall } & \multicolumn{3}{|c|}{ satfood } \\
\hline & $\operatorname{mean}^{a}$ & $\mathrm{sd}^{a}$ & $95 \% \mathrm{ci}^{a}$ & mean & sd & $95 \% \mathrm{ci}$ \\
\hline intercept & 1.0801 & 0.0488 & $(0.9856,1.1751)$ & 1.0228 & 0.0476 & $(0.9300,1.1174)$ \\
\hline fem & 0.0723 & 0.0174 & $(0.0387,0.1065)$ & 0.0071 & 0.0168 & $(-0.0255,0.0399)$ \\
\hline age1 & -0.0804 & 0.0546 & $(-0.1864,0.0268)$ & -0.0341 & 0.0541 & $(-0.1400,0.0717)$ \\
\hline age3 & -0.0783 & 0.0310 & $(-0.1395,-0.0181)$ & -0.0792 & 0.0303 & $(-0.1390,-0.0203)$ \\
\hline age 4 & -0.1267 & 0.0323 & $(-0.1904,-0.0635)$ & -0.1292 & 0.0313 & $(-0.1901,-0.0684)$ \\
\hline age5 & -0.0732 & 0.0281 & $(-0.1287,-0.0191)$ & -0.0697 & 0.0270 & $(-0.1229,-0.0166)$ \\
\hline age6 & 0.0429 & 0.0271 & $(-0.0102,0.0951)$ & 0.0302 & 0.0268 & $(-0.0232,0.0826)$ \\
\hline reg1 & -0.0022 & 0.0376 & $(-0.0763,0.0730)$ & -0.0251 & 0.0366 & $(-0.0962,0.0470)$ \\
\hline reg3 & -0.0372 & 0.0370 & $(-0.1094,0.0353)$ & 0.0099 & 0.0361 & $(-0.0609,0.0819)$ \\
\hline reg4 & -0.0223 & 0.0272 & $(-0.0747,0.0305)$ & -0.0112 & 0.0264 & $(-0.0627,0.0403)$ \\
\hline reg5 & -0.0599 & 0.0245 & $(-0.1076,-0.0120)$ & -0.0549 & 0.0239 & $(-0.1016,-0.0081)$ \\
\hline reg6 & -0.0278 & 0.0367 & $(-0.1001,0.0439)$ & -0.0205 & 0.0359 & $(-0.0915,0.0500)$ \\
\hline reg7 & -0.0221 & 0.0492 & $(-0.1186,0.0740)$ & 0.0812 & 0.0489 & $(-0.0159,0.1775)$ \\
\hline reg8 & 0.0045 & 0.0293 & $(-0.0525,0.0623)$ & -0.0116 & 0.0288 & $(-0.0674,0.0452)$ \\
\hline pack1 & -0.0330 & 0.0288 & $(-0.0891,0.0239)$ & -0.1333 & 0.0261 & $(-0.1838,-0.0823)$ \\
\hline pack2 & -0.0259 & 0.0245 & $(-0.0745,0.0220)$ & -0.0536 & 0.0239 & $(-0.0999,-0.0071)$ \\
\hline tour 1 & -0.0932 & 0.0276 & $(-0.1478,-0.0390)$ & -0.0969 & 0.0272 & $(-0.1501,-0.0440)$ \\
\hline tour2 & -0.0214 & 0.0245 & $(-0.0698,0.0266)$ & -0.0508 & 0.0246 & $(-0.0990,-0.0030)$ \\
\hline tour3 & -0.0911 & 0.0315 & $(-0.1526,-0.0294)$ & -0.0660 & 0.0317 & $(-0.1280,-0.0042)$ \\
\hline tour5 & -0.0825 & 0.0349 & $(-0.1511,-0.0146)$ & -0.0804 & 0.0344 & $(-0.1481,-0.0131)$ \\
\hline tour6 & 0.0746 & 0.0667 & $(-0.0562,0.2065)$ & 0.0512 & 0.0642 & $(-0.0752,0.1762)$ \\
\hline day1 & -0.0338 & 0.0330 & $(-0.0991,0.0309)$ & 0.0068 & 0.0329 & $(-0.0579,0.0713)$ \\
\hline day3 & -0.0230 & 0.0207 & $(-0.0638,0.0175)$ & -0.0309 & 0.0203 & $(-0.0711,0.0085)$ \\
\hline day4 & 0.0234 & 0.0315 & $(-0.0386,0.0856)$ & 0.0356 & 0.0306 & $(-0.0239,0.0951)$ \\
\hline day5 & 0.0376 & 0.0550 & $(-0.0708,0.1475)$ & 0.0258 & 0.0537 & $(-0.0793,0.1313)$ \\
\hline day 6 & 0.1233 & 0.0693 & $(-0.0131,0.2592)$ & 0.1349 & 0.0690 & $(0.0005,0.2690)$ \\
\hline day7 & 0.0606 & 0.0525 & $(-0.0420,0.1634)$ & -0.0253 & 0.0501 & $(-0.1246,0.0719)$ \\
\hline time2 & -0.0132 & 0.0214 & $(-0.0539,0.0298)$ & -0.0029 & 0.0206 & $(-0.0437,0.0368)$ \\
\hline time3 & -0.0670 & 0.0245 & $(-0.1147,-0.0180)$ & 0.0014 & 0.0241 & $(-0.0455,0.0481)$ \\
\hline $\operatorname{tran} 1$ & -0.0171 & 0.0222 & $(-0.0603,0.0268)$ & & & \\
\hline $\operatorname{tran} 2$ & -0.0137 & 0.0191 & $(-0.0509,0.0237)$ & & & \\
\hline $\operatorname{tran} 3$ & -0.0486 & 0.0260 & $(-0.1000,0.0015)$ & & & \\
\hline $\operatorname{tran} 4$ & 0.0613 & 0.0346 & $(-0.0068,0.1293)$ & & & \\
\hline $\operatorname{tran} 6$ & 0.2841 & 0.0799 & $(0.1289,0.4429)$ & & & \\
\hline $\operatorname{tran} 7$ & 0.0090 & 0.0252 & $(-0.0413,0.0569)$ & & & \\
\hline $\operatorname{tran} 8$ & 0.0125 & 0.0899 & $(-0.1591,0.1910)$ & & & \\
\hline $\operatorname{tran} 9$ & -0.0273 & 0.0620 & $(-0.1482,0.0962)$ & & & \\
\hline $\operatorname{tran} 10$ & 0.0619 & 0.0433 & $(-0.0229,0.1474)$ & & & \\
\hline accom 1 & -0.0082 & 0.0148 & $(-0.0372,0.0211)$ & -0.0100 & 0.0163 & $(-0.0415,0.0220)$ \\
\hline accom2 & 0.0035 & 0.0174 & $(-0.0303,0.0378)$ & -0.0380 & 0.0190 & $(-0.0749,-0.0006)$ \\
\hline accom3 & -0.0489 & 0.0427 & $(-0.1326,0.0349)$ & -0.0771 & 0.0469 & $(-0.1680,0.0143)$ \\
\hline accom 4 & -0.0122 & 0.0349 & $(-0.0801,0.0558)$ & 0.0214 & 0.0377 & $(-0.0512,0.0960)$ \\
\hline accom5 & -0.1422 & 0.0746 & $(-0.2887,0.0038)$ & -0.0073 & 0.0851 & $(-0.1725,0.1606)$ \\
\hline accom 6 & 0.0054 & 0.0314 & $(-0.0554,0.0681)$ & 0.0525 & 0.0342 & $(-0.0139,0.1191)$ \\
\hline accom7 & -0.0494 & 0.0608 & $(-0.1683,0.0704)$ & -0.0105 & 0.0569 & $(-0.1234,0.1010)$ \\
\hline accom8 & -0.0324 & 0.0549 & $(-0.1396,0.0752)$ & 0.0430 & 0.0593 & $(-0.0728,0.1596)$ \\
\hline accom 9 & 0.0460 & 0.0522 & $(-0.0552,0.1486)$ & -0.0065 & 0.0542 & $(-0.1113,0.0998)$ \\
\hline route1 & 0.0072 & 0.0232 & $(-0.0386,0.0520)$ & 0.0186 & 0.0227 & $(-0.0266,0.0634)$ \\
\hline route2 & 0.0143 & 0.0292 & $(-0.0429,0.0702)$ & 0.0325 & 0.0288 & $(-0.0238,0.0883)$ \\
\hline route 3 & -0.0253 & 0.0227 & $(-0.0700,0.0190)$ & -0.0335 & 0.0222 & $(-0.0768,0.0097)$ \\
\hline route 4 & 0.0641 & 0.0422 & $(-0.0192,0.1465)$ & 0.0701 & 0.0408 & $(-0.0095,0.1506)$ \\
\hline route5 & -0.0240 & 0.0384 & $(-0.0989,0.0511)$ & -0.0523 & 0.0369 & $(-0.1240,0.0210)$ \\
\hline route 6 & 0.0142 & 0.0284 & $(-0.0412,0.0698)$ & 0.0250 & 0.0273 & $(-0.0280,0.0788)$ \\
\hline route7 & 0.0992 & 0.0331 & $(0.0344,0.1638)$ & 0.0705 & 0.0318 & $(0.0080,0.1328)$ \\
\hline
\end{tabular}

$a$ : 'mean,' 'sd' and '95\% ci' denote the posterior mean, posterior standard deviation and $95 \%$ credible interval, respectively. 
Tables 3: Continued

\begin{tabular}{|c|c|c|c|c|c|c|}
\hline & \multicolumn{3}{|c|}{ satsouv } & \multicolumn{3}{|c|}{ sataccom } \\
\hline & mean $^{a}$ & $\mathrm{sd}^{a}$ & $95 \% \mathrm{ci}^{a}$ & mean & $\mathrm{sd}$ & $95 \% \mathrm{ci}$ \\
\hline intercept & 0.8776 & 0.0362 & $(0.8075,0.9500)$ & 0.8640 & 0.0451 & $(0.7762,0.9518)$ \\
\hline fem & 0.0502 & 0.0136 & $(0.0238,0.0768)$ & 0.0118 & 0.0160 & $(-0.0195,0.0431)$ \\
\hline age1 & 0.0164 & 0.0436 & $(-0.0706,0.1020)$ & -0.0091 & 0.0511 & $(-0.1091,0.0920)$ \\
\hline age3 & -0.0801 & 0.0243 & $(-0.1283,-0.0333)$ & -0.0571 & 0.0286 & $(-0.1139,-0.0014)$ \\
\hline age4 & -0.0704 & 0.0255 & $(-0.1209,-0.0203)$ & -0.0849 & 0.0297 & $(-0.1438,-0.0272)$ \\
\hline age5 & -0.0598 & 0.0218 & $(-0.1029,-0.0172)$ & -0.0468 & 0.0257 & $(-0.0979,0.0037)$ \\
\hline age 6 & 0.0031 & 0.0216 & $(-0.0398,0.0446)$ & 0.0466 & 0.0255 & $(-0.0038,0.0956)$ \\
\hline reg1 & -0.0103 & 0.0297 & $(-0.0689,0.0481)$ & 0.0153 & 0.0349 & $(-0.0515,0.0843)$ \\
\hline reg3 & 0.0225 & 0.0295 & $(-0.0354,0.0799)$ & -0.0017 & 0.0343 & $(-0.0692,0.0655)$ \\
\hline reg4 & -0.0099 & 0.0217 & $(-0.0523,0.0324)$ & -0.0503 & 0.0252 & $(-0.1003,-0.0011)$ \\
\hline reg5 & -0.0435 & 0.0195 & $(-0.0820,-0.0053)$ & -0.0250 & 0.0229 & $(-0.0693,0.0203)$ \\
\hline reg6 & 0.0145 & 0.0294 & $(-0.0431,0.0719)$ & 0.0384 & 0.0346 & $(-0.0289,0.1062)$ \\
\hline reg7 & 0.0262 & 0.0392 & $(-0.0503,0.1032)$ & -0.0043 & 0.0463 & $(-0.0955,0.0876)$ \\
\hline reg8 & -0.0103 & 0.0234 & $(-0.0567,0.0352)$ & 0.0387 & 0.0278 & $(-0.0165,0.0925)$ \\
\hline pack1 & -0.0482 & 0.0209 & $(-0.0891,-0.0070)$ & -0.0422 & 0.0252 & $(-0.0918,0.0065)$ \\
\hline pack2 & -0.0265 & 0.0191 & $(-0.0638,0.0107)$ & -0.0050 & 0.0228 & $(-0.0502,0.0395)$ \\
\hline tour1 & -0.0371 & 0.0218 & $(-0.0808,0.0053)$ & -0.0699 & 0.0259 & $(-0.1209,-0.0193)$ \\
\hline tour2 & -0.0024 & 0.0197 & $(-0.0409,0.0363)$ & 0.0233 & 0.0231 & $(-0.0217,0.0686)$ \\
\hline tour3 & -0.0202 & 0.0257 & $(-0.0708,0.0299)$ & -0.0243 & 0.0297 & $(-0.0830,0.0337)$ \\
\hline tour5 & -0.0741 & 0.0274 & $(-0.1277,-0.0200)$ & -0.0207 & 0.0317 & $(-0.0831,0.0419)$ \\
\hline tour6 & 0.0294 & 0.0507 & $(-0.0704,0.1283)$ & 0.1547 & 0.0618 & $(0.0352,0.2766)$ \\
\hline day1 & 0.0325 & 0.0263 & $(-0.0195,0.0847)$ & 0.0116 & 0.0315 & $(-0.0499,0.0730)$ \\
\hline day3 & -0.0280 & 0.0164 & $(-0.0605,0.0038)$ & -0.0148 & 0.0191 & $(-0.0526,0.0224)$ \\
\hline day4 & 0.0217 & 0.0247 & $(-0.0275,0.0695)$ & 0.0193 & 0.0293 & $(-0.0383,0.0756)$ \\
\hline day5 & 0.0096 & 0.0422 & $(-0.0732,0.0927)$ & 0.0391 & 0.0501 & $(-0.0584,0.1377)$ \\
\hline day6 & 0.0706 & 0.0530 & $(-0.0328,0.1744)$ & 0.0864 & 0.0637 & $(-0.0375,0.2107)$ \\
\hline day7 & -0.0535 & 0.0374 & $(-0.1260,0.0200)$ & -0.0328 & 0.0474 & $(-0.1258,0.0595)$ \\
\hline time2 & 0.0053 & 0.0168 & $(-0.0279,0.0384)$ & 0.0019 & 0.0199 & $(-0.0368,0.0412)$ \\
\hline time3 & -0.0282 & 0.0194 & $(-0.0662,0.0099)$ & 0.0051 & 0.0231 & $(-0.0403,0.0500)$ \\
\hline accom 1 & & & & 0.0107 & 0.0168 & $(-0.0221,0.0437)$ \\
\hline accom2 & & & & 0.0355 & 0.0197 & $(-0.0033,0.0740)$ \\
\hline accom3 & & & & -0.0528 & 0.0496 & $(-0.1496,0.0433)$ \\
\hline accom 4 & & & & -0.0419 & 0.0380 & $(-0.1171,0.0324)$ \\
\hline accom5 & & & & -0.1010 & 0.0871 & $(-0.2713,0.0704)$ \\
\hline accom6 & & & & -0.0730 & 0.0347 & $(-0.1416,-0.0058)$ \\
\hline accom7 & & & & -0.0059 & 0.0578 & $(-0.1182,0.1078)$ \\
\hline accom8 & & & & 0.1521 & 0.0593 & $(0.0348,0.2672)$ \\
\hline accom 9 & & & & -0.1427 & 0.0536 & $(-0.2476,-0.0377)$ \\
\hline route1 & 0.0077 & 0.0182 & $(-0.0279,0.0435)$ & -0.0324 & 0.0212 & $(-0.0741,0.0092)$ \\
\hline route2 & 0.0290 & 0.0231 & $(-0.0163,0.0743)$ & -0.0006 & 0.0276 & $(-0.0547,0.0528)$ \\
\hline route3 & -0.0311 & 0.0178 & $(-0.0658,0.0037)$ & -0.0065 & 0.0207 & $(-0.0477,0.0339)$ \\
\hline route4 & 0.0303 & 0.0326 & $(-0.0335,0.0940)$ & -0.0192 & 0.0387 & $(-0.0945,0.0571)$ \\
\hline route5 & 0.0047 & 0.0300 & $(-0.0538,0.0637)$ & -0.0419 & 0.0355 & $(-0.1115,0.0264)$ \\
\hline route 6 & -0.0031 & 0.0222 & $(-0.0469,0.0401)$ & -0.0135 & 0.0263 & $(-0.0650,0.0382)$ \\
\hline route7 & 0.0371 & 0.0255 & $(-0.0131,0.0876)$ & 0.0487 & 0.0303 & $(-0.0102,0.1084)$ \\
\hline
\end{tabular}

$a$ : 'mean,' 'sd' and '95\% ci' denote the posterior mean, posterior standard deviation and $95 \%$ credible interval, respectively. 
Tables 3: Continued

\begin{tabular}{|c|c|c|c|c|c|c|}
\hline & \multicolumn{3}{|c|}{ satserv } & \multicolumn{3}{|c|}{ sattran } \\
\hline & $\operatorname{mean}^{a}$ & $\mathrm{sd}^{a}$ & $95 \% \mathrm{ci}^{a}$ & mean & sd & $95 \% \mathrm{ci}$ \\
\hline intercept & 0.7956 & 0.0405 & $(0.7177,0.8749)$ & 0.6946 & 0.0401 & $(0.6162,0.7745)$ \\
\hline fem & 0.0324 & 0.0138 & $(0.0058,0.0595)$ & 0.0257 & 0.0148 & $(-0.0033,0.0546)$ \\
\hline age1 & -0.0760 & 0.0441 & $(-0.1618,0.0115)$ & -0.0710 & 0.0468 & $(-0.1628,0.0199)$ \\
\hline age3 & -0.0389 & 0.0250 & $(-0.0881,0.0103)$ & -0.0004 & 0.0262 & $(-0.0527,0.0506)$ \\
\hline age4 & -0.0746 & 0.0258 & $(-0.1250,-0.0238)$ & -0.0089 & 0.0275 & $(-0.0623,0.0452)$ \\
\hline age5 & -0.0332 & 0.0225 & $(-0.0773,0.0106)$ & -0.0051 & 0.0237 & $(-0.0522,0.0409)$ \\
\hline age6 & 0.0418 & 0.0221 & $(-0.0020,0.0842)$ & 0.0545 & 0.0233 & $(0.0091,0.1001)$ \\
\hline reg1 & 0.0157 & 0.0305 & $(-0.0430,0.0767)$ & 0.0471 & 0.0323 & $(-0.0153,0.1115)$ \\
\hline reg3 & -0.0337 & 0.0297 & $(-0.0916,0.0248)$ & 0.0852 & 0.0314 & $(0.0240,0.1470)$ \\
\hline reg4 & -0.0313 & 0.0218 & $(-0.0743,0.0112)$ & -0.0291 & 0.0233 & $(-0.0744,0.0169)$ \\
\hline reg5 & -0.0632 & 0.0202 & $(-0.1023,-0.0238)$ & -0.0122 & 0.0213 & $(-0.0538,0.0297)$ \\
\hline reg6 & 0.0140 & 0.0292 & $(-0.0429,0.0713)$ & 0.0214 & 0.0316 & $(-0.0401,0.0832)$ \\
\hline reg7 & 0.0003 & 0.0402 & $(-0.0787,0.0780)$ & -0.0225 & 0.0429 & $(-0.1079,0.0613)$ \\
\hline reg8 & -0.0147 & 0.0240 & $(-0.0614,0.0322)$ & 0.0326 & 0.0255 & $(-0.0172,0.0824)$ \\
\hline pack1 & -0.0304 & 0.0242 & $(-0.0777,0.0169)$ & -0.0159 & 0.0268 & $(-0.0681,0.0372)$ \\
\hline pack2 & 0.0216 & 0.0197 & $(-0.0173,0.0599)$ & -0.0180 & 0.0206 & $(-0.0580,0.0223)$ \\
\hline tour 1 & -0.0369 & 0.0227 & $(-0.0816,0.0078)$ & 0.0021 & 0.0241 & $(-0.0456,0.0487)$ \\
\hline tour2 & 0.0185 & 0.0201 & $(-0.0207,0.0581)$ & 0.0031 & 0.0214 & $(-0.0385,0.0450)$ \\
\hline tour3 & -0.0106 & 0.0258 & $(-0.0612,0.0396)$ & -0.0248 & 0.0275 & $(-0.0792,0.0291)$ \\
\hline tour5 & -0.0263 & 0.0280 & $(-0.0809,0.0281)$ & -0.0505 & 0.0300 & $(-0.1096,0.0076)$ \\
\hline tour6 & 0.0872 & 0.0526 & $(-0.0139,0.1898)$ & 0.0832 & 0.0551 & $(-0.0247,0.1909)$ \\
\hline day1 & -0.0256 & 0.0272 & $(-0.0796,0.0276)$ & -0.0053 & 0.0284 & $(-0.0598,0.0512)$ \\
\hline day3 & -0.0253 & 0.0166 & $(-0.0580,0.0069)$ & -0.0317 & 0.0177 & $(-0.0669,0.0030)$ \\
\hline day4 & 0.0134 & 0.0251 & $(-0.0361,0.0623)$ & -0.0425 & 0.0268 & $(-0.0951,0.0099)$ \\
\hline day5 & -0.0099 & 0.0437 & $(-0.0952,0.0757)$ & -0.0903 & 0.0464 & $(-0.1806,0.0008)$ \\
\hline day 6 & 0.0638 & 0.0552 & $(-0.0444,0.1733)$ & 0.0289 & 0.0575 & $(-0.0824,0.1439)$ \\
\hline day7 & -0.0176 & 0.0415 & $(-0.0989,0.0624)$ & -0.1123 & 0.0432 & $(-0.1960,-0.0278)$ \\
\hline time2 & -0.0054 & 0.0173 & $(-0.0392,0.0286)$ & -0.0233 & 0.0182 & $(-0.0589,0.0125)$ \\
\hline time3 & -0.0090 & 0.0198 & $(-0.0477,0.0299)$ & -0.0357 & 0.0213 & $(-0.0780,0.0063)$ \\
\hline $\operatorname{tran} 1$ & 0.0485 & 0.0202 & $(0.0090,0.0881)$ & 0.0055 & 0.0251 & $(-0.0433,0.0550)$ \\
\hline $\operatorname{tran} 2$ & 0.0356 & 0.0173 & $(0.0015,0.0690)$ & 0.0569 & 0.0210 & $(0.0154,0.0983)$ \\
\hline $\operatorname{tran} 3$ & 0.0448 & 0.0240 & $(-0.0018,0.0922)$ & 0.0688 & 0.0299 & $(0.0115,0.1275)$ \\
\hline $\operatorname{tran} 4$ & 0.0352 & 0.0301 & $(-0.0237,0.0947)$ & 0.0389 & 0.0366 & $(-0.0336,0.1105)$ \\
\hline $\operatorname{tran} 6$ & -0.0127 & 0.0580 & $(-0.1274,0.1015)$ & 0.0709 & 0.0662 & $(-0.0595,0.1993)$ \\
\hline $\operatorname{tran} 7$ & 0.0504 & 0.0230 & $(0.0053,0.0951)$ & -0.0279 & 0.0281 & $(-0.0834,0.0270)$ \\
\hline $\operatorname{tran} 8$ & -0.0990 & 0.0740 & $(-0.2455,0.0464)$ & -0.1289 & 0.0951 & $(-0.3134,0.0584)$ \\
\hline $\operatorname{tran} 9$ & 0.0165 & 0.0568 & $(-0.0953,0.1284)$ & 0.0886 & 0.0719 & $(-0.0510,0.2297)$ \\
\hline $\operatorname{tran} 10$ & 0.0781 & 0.0394 & $(0.0009,0.1542)$ & 0.0274 & 0.0475 & $(-0.0653,0.1201)$ \\
\hline accom 1 & 0.0114 & 0.0139 & $(-0.0158,0.0387)$ & & & \\
\hline accom2 & 0.0098 & 0.0165 & $(-0.0225,0.0418)$ & & & \\
\hline accom3 & -0.0340 & 0.0414 & $(-0.1151,0.0473)$ & & & \\
\hline accom 4 & -0.0152 & 0.0319 & $(-0.0785,0.0467)$ & & & \\
\hline accom5 & -0.0649 & 0.0727 & $(-0.2069,0.0781)$ & & & \\
\hline accom 6 & -0.0139 & 0.0291 & $(-0.0704,0.0430)$ & & & \\
\hline $\operatorname{accom} 7$ & -0.0027 & 0.0521 & $(-0.1040,0.1002)$ & & & \\
\hline accom8 & 0.0993 & 0.0481 & $(0.0042,0.1936)$ & & & \\
\hline accom 9 & -0.1251 & 0.0441 & $(-0.2112,-0.0386)$ & & & \\
\hline route1 & -0.0166 & 0.0184 & $(-0.0527,0.0193)$ & 0.0091 & 0.0194 & $(-0.0294,0.0467)$ \\
\hline route2 & -0.0052 & 0.0240 & $(-0.0526,0.0413)$ & -0.0062 & 0.0252 & $(-0.0556,0.0431)$ \\
\hline route 3 & -0.0190 & 0.0182 & $(-0.0550,0.0165)$ & -0.0199 & 0.0195 & $(-0.0583,0.0184)$ \\
\hline route 4 & 0.0436 & 0.0338 & $(-0.0225,0.1110)$ & -0.0117 & 0.0360 & $(-0.0815,0.0592)$ \\
\hline route5 & -0.0279 & 0.0306 & $(-0.0870,0.0316)$ & 0.0294 & 0.0326 & $(-0.0360,0.0941)$ \\
\hline route 6 & 0.0116 & 0.0233 & $(-0.0341,0.057)$ & -0.0010 & 0.0243 & $(-0.0477,0.0466)$ \\
\hline route7 & 0.0394 & 0.0263 & $(-0.0125,0.0906)$ & 0.0368 & 0.0279 & $(-0.0193,0.0908)$ \\
\hline
\end{tabular}

$a$ : 'mean,' 'sd' and '95\% ci' denote the posterior mean, posterior standard deviation and $95 \%$ credible interval, respectively. 
Tables 3: Continued

\begin{tabular}{|c|c|c|c|c|c|c|}
\hline & \multicolumn{3}{|c|}{ satequip } & \multicolumn{3}{|c|}{ satview } \\
\hline & mean $^{a}$ & $\mathrm{sd}^{a}$ & $95 \% \mathrm{ci}^{a}$ & mean & $\mathrm{sd}$ & $95 \%$ ci \\
\hline intercept & 0.7842 & 0.0402 & $(0.7071,0.8636)$ & 1.1196 & 0.0482 & $(1.0267,1.2152)$ \\
\hline fem & 0.0403 & 0.0137 & $(0.0139,0.0670)$ & 0.0787 & 0.0187 & $(0.0422,0.1158)$ \\
\hline age1 & -0.0458 & 0.0436 & $(-0.1321,0.0380)$ & -0.1010 & 0.0570 & $(-0.2118,0.0116)$ \\
\hline age3 & -0.0332 & 0.0245 & $(-0.0812,0.0146)$ & -0.0437 & 0.0327 & $(-0.1082,0.0192)$ \\
\hline age4 & -0.0903 & 0.0255 & $(-0.1411,-0.0408)$ & -0.0944 & 0.0339 & $(-0.1601,-0.0278)$ \\
\hline age5 & -0.0700 & 0.0220 & $(-0.1139,-0.0279)$ & -0.0580 & 0.0291 & $(-0.1154,-0.0012)$ \\
\hline age 6 & -0.0200 & 0.0218 & $(-0.0633,0.0222)$ & 0.0528 & 0.0289 & $(-0.0039,0.1091)$ \\
\hline reg1 & -0.0072 & 0.0300 & $(-0.0650,0.0522)$ & -0.0059 & 0.0393 & $(-0.0830,0.0725)$ \\
\hline reg3 & 0.0412 & 0.0296 & $(-0.0169,0.0995)$ & 0.0081 & 0.0398 & $(-0.0696,0.0864)$ \\
\hline reg4 & -0.0120 & 0.0217 & $(-0.0541,0.0306)$ & 0.0106 & 0.0292 & $(-0.0460,0.0678)$ \\
\hline reg5 & -0.0258 & 0.0197 & $(-0.0640,0.0130)$ & -0.0170 & 0.0262 & $(-0.0684,0.0345)$ \\
\hline reg6 & 0.0326 & 0.0293 & $(-0.0252,0.0898)$ & 0.0181 & 0.0393 & $(-0.0588,0.0955)$ \\
\hline reg7 & -0.0178 & 0.0393 & $(-0.0951,0.0590)$ & 0.0475 & 0.0539 & $(-0.0584,0.1534)$ \\
\hline reg8 & 0.0011 & 0.0234 & $(-0.0446,0.0465)$ & 0.0326 & 0.0314 & $(-0.0286,0.0944)$ \\
\hline pack1 & -0.0367 & 0.0246 & $(-0.0849,0.0113)$ & -0.0451 & 0.0279 & $(-0.0988,0.0098)$ \\
\hline pack2 & -0.0086 & 0.0195 & $(-0.0468,0.0296)$ & -0.0304 & 0.0258 & $(-0.0814,0.0199)$ \\
\hline tour1 & -0.0243 & 0.0225 & $(-0.0687,0.0194)$ & -0.0803 & 0.0291 & $(-0.1364,-0.0233)$ \\
\hline tour2 & -0.0138 & 0.0199 & $(-0.0529,0.0251)$ & -0.0218 & 0.0263 & $(-0.0736,0.0298)$ \\
\hline tour3 & -0.0111 & 0.0257 & $(-0.0611,0.0398)$ & -0.1227 & 0.0333 & $(-0.1877,-0.0571)$ \\
\hline tour5 & -0.0671 & 0.0279 & $(-0.1223,-0.0126)$ & -0.0479 & 0.0368 & $(-0.1185,0.0246)$ \\
\hline tour6 & 0.0021 & 0.0514 & $(-0.0978,0.1048)$ & 0.1089 & 0.0731 & $(-0.0318,0.2552)$ \\
\hline day1 & -0.0289 & 0.0264 & $(-0.0803,0.0225)$ & -0.0490 & 0.0344 & $(-0.1169,0.0184)$ \\
\hline day3 & -0.0155 & 0.0166 & $(-0.0477,0.0167)$ & -0.0129 & 0.0221 & $(-0.0555,0.0307)$ \\
\hline day4 & -0.0005 & 0.0252 & $(-0.0500,0.0491)$ & 0.0009 & 0.0333 & $(-0.0645,0.0654)$ \\
\hline day5 & -0.0041 & 0.0434 & $(-0.0900,0.0804)$ & 0.0125 & 0.0591 & $(-0.1026,0.1295)$ \\
\hline day6 & 0.0470 & 0.0536 & $(-0.0573,0.1513)$ & 0.1449 & 0.0754 & $(-0.0013,0.2955)$ \\
\hline day7 & -0.0071 & 0.0415 & $(-0.0883,0.0732)$ & 0.0937 & 0.0538 & $(-0.0110,0.1997)$ \\
\hline time2 & -0.0222 & 0.0169 & $(-0.0548,0.0108)$ & -0.0226 & 0.0228 & $(-0.0667,0.0219)$ \\
\hline time3 & -0.0342 & 0.0196 & $(-0.0729,0.0048)$ & -0.0507 & 0.0261 & $(-0.1020,0.0003)$ \\
\hline $\operatorname{tran} 1$ & 0.0131 & 0.0218 & $(-0.0295,0.0563)$ & & & \\
\hline $\operatorname{tran} 2$ & 0.0251 & 0.0186 & $(-0.0109,0.0615)$ & & & \\
\hline $\operatorname{tran} 3$ & -0.0108 & 0.0256 & $(-0.0612,0.0397)$ & & & \\
\hline $\operatorname{tran} 4$ & 0.0521 & 0.0325 & $(-0.0109,0.1159)$ & & & \\
\hline $\operatorname{tran} 6$ & 0.1485 & 0.0642 & $(0.0229,0.2752)$ & & & \\
\hline $\operatorname{tran} 7$ & -0.0033 & 0.0249 & $(-0.0517,0.0457)$ & & & \\
\hline $\operatorname{tran} 8$ & 0.0207 & 0.0826 & $(-0.1402,0.1831)$ & & & \\
\hline $\operatorname{tran} 9$ & 0.0138 & 0.0611 & $(-0.1059,0.1341)$ & & & \\
\hline $\operatorname{tran} 10$ & 0.0022 & 0.0411 & $(-0.0780,0.0837)$ & & & \\
\hline accom 1 & -0.0197 & 0.0134 & $(-0.0457,0.0069)$ & & & \\
\hline accom2 & 0.0276 & 0.0156 & $(-0.0028,0.0584)$ & & & \\
\hline accom3 & 0.0035 & 0.0404 & $(-0.0753,0.0825)$ & & & \\
\hline accom 4 & -0.0297 & 0.0312 & $(-0.0908,0.0318)$ & & & \\
\hline accom5 & -0.1001 & 0.0675 & $(-0.2324,0.0337)$ & & & \\
\hline accom6 & -0.0222 & 0.0282 & $(-0.0773,0.0327)$ & & & \\
\hline accom7 & -0.0263 & 0.0511 & $(-0.1267,0.0738)$ & & & \\
\hline accom8 & 0.0866 & 0.0475 & $(-0.0057,0.1801)$ & & & \\
\hline accom 9 & -0.0449 & 0.0430 & $(-0.1297,0.0389)$ & & & \\
\hline route1 & 0.0115 & 0.0183 & $(-0.0250,0.0472)$ & 0.0626 & 0.0245 & $(0.0146,0.1100)$ \\
\hline route2 & 0.0041 & 0.0239 & $(-0.0435,0.0506)$ & -0.0223 & 0.0318 & $(-0.0849,0.0395)$ \\
\hline route3 & 0.0160 & 0.0180 & $(-0.0196,0.0510)$ & 0.0355 & 0.0241 & $(-0.0112,0.0830)$ \\
\hline route 4 & 0.0207 & 0.0338 & $(-0.0458,0.0865)$ & 0.0736 & 0.0460 & $(-0.0168,0.1640)$ \\
\hline route5 & -0.0350 & 0.0303 & $(-0.0935,0.0244)$ & -0.0792 & 0.0414 & $(-0.1614,0.0003)$ \\
\hline route6 & 0.0012 & 0.0225 & $(-0.0431,0.0451)$ & 0.0477 & 0.0307 & $(-0.0118,0.1076)$ \\
\hline route7 & 0.0820 & 0.0262 & $(0.0311,0.1336)$ & 0.1642 & 0.0361 & $(0.0931,0.2345)$ \\
\hline
\end{tabular}

$a$ : 'mean,' 'sd' and '95\% ci' denote the posterior mean, posterior standard deviation and $95 \%$ credible interval, respectively. 
Table 4: The posterior results of $\Sigma$

\begin{tabular}{l|ccc}
\hline & $\mathrm{mean}^{a}$ & $\mathrm{sd}^{a}$ & $95 \% \mathrm{ci}^{a}$ \\
\hline$\sigma_{11}$ & 0.1899 & 0.0100 & $(0.1711,0.2105)$ \\
$\sigma_{21}$ & 0.1283 & 0.0061 & $(0.1167,0.1407)$ \\
$\sigma_{31}$ & 0.1021 & 0.0050 & $(0.0926,0.1122)$ \\
$\sigma_{41}$ & 0.1140 & 0.0056 & $(0.1034,0.1254)$ \\
$\sigma_{51}$ & 0.1027 & 0.0050 & $(0.0933,0.1129)$ \\
$\sigma_{61}$ & 0.0915 & 0.0047 & $(0.0827,0.1010)$ \\
$\sigma_{71}$ & 0.0988 & 0.0047 & $(0.0899,0.1084)$ \\
$\sigma_{81}$ & 0.1501 & 0.0078 & $(0.1355,0.1660)$ \\
$\sigma_{22}$ & 0.1910 & 0.0077 & $(0.1764,0.2064)$ \\
$\sigma_{32}$ & 0.1099 & 0.0048 & $(0.1008,0.1196)$ \\
$\sigma_{42}$ & 0.1082 & 0.0050 & $(0.0986,0.1184)$ \\
$\sigma_{52}$ & 0.0882 & 0.0042 & $(0.0800,0.0965)$ \\
$\sigma_{62}$ & 0.0777 & 0.0041 & $(0.0699,0.0861)$ \\
$\sigma_{72}$ & 0.0805 & 0.0040 & $(0.0729,0.0887)$ \\
$\sigma_{82}$ & 0.0998 & 0.0058 & $(0.0889,0.1119)$ \\
$\sigma_{33}$ & 0.1246 & 0.0061 & $(0.1129,0.1371)$ \\
$\sigma_{43}$ & 0.0821 & 0.0041 & $(0.0743,0.0904)$ \\
$\sigma_{53}$ & 0.0706 & 0.0036 & $(0.0638,0.0777)$ \\
$\sigma_{63}$ & 0.0684 & 0.0035 & $(0.0617,0.0754)$ \\
$\sigma_{73}$ & 0.0708 & 0.0034 & $(0.0642,0.0778)$ \\
$\sigma_{83}$ & 0.0819 & 0.0049 & $(0.0727,0.0917)$ \\
$\sigma_{44}$ & 0.1743 & 0.0073 & $(0.1605,0.1891)$ \\
$\sigma_{54}$ & 0.1109 & 0.0047 & $(0.1020,0.1203)$ \\
$\sigma_{64}$ & 0.0822 & 0.0041 & $(0.0744,0.0904)$ \\
$\sigma_{74}$ & 0.0801 & 0.0039 & $(0.0727,0.0880)$ \\
$\sigma_{84}$ & 0.0865 & 0.0054 & $(0.0762,0.0975)$ \\
$\sigma_{55}$ & 0.1300 & 0.0056 & $(0.1193,0.1415)$ \\
$\sigma_{65}$ & 0.0823 & 0.0037 & $(0.0752,0.0899)$ \\
$\sigma_{75}$ & 0.0764 & 0.0035 & $(0.0697,0.0835)$ \\
$\sigma_{85}$ & 0.0873 & 0.0050 & $(0.0778,0.0974)$ \\
$\sigma_{66}$ & 0.1477 & 0.0051 & $(0.1379,0.1580)$ \\
& 0.0828 & 0.0036 & $(0.0759,0.0901)$ \\
& 0.0810 & 0.0050 & $(0.0717,0.0912)$ \\
& 0.0953 & 0.0051 & $(0.0855,0.1057)$ \\
& 0.0126 & $(0.1806,0.2297)$ \\
\hline
\end{tabular}

a: 'mean,' 'sd' and '95\% ci' denote the posterior mean, posterior standard deviation and 95\% credible interval, respectively. 
Table 5: The posterior results of $\gamma$

\begin{tabular}{c|ccc}
\hline & $\mathrm{mean}^{a}$ & $\mathrm{sd}^{a}$ & $95 \% \mathrm{ci}^{a}$ \\
\hline$\gamma_{12}$ & 0.1261 & 0.0172 & $(0.0940,0.1611)$ \\
$\gamma_{13}$ & 0.5792 & 0.0118 & $(0.5561,0.6017)$ \\
$\gamma_{22}$ & 0.2437 & 0.0127 & $(0.2187,0.2685)$ \\
$\gamma_{23}$ & 0.6284 & 0.0093 & $(0.6099,0.6461)$ \\
$\gamma_{32}$ & 0.2288 & 0.0171 & $(0.1952,0.2625)$ \\
$\gamma_{33}$ & 0.6913 & 0.0090 & $(0.6738,0.7086)$ \\
$\gamma_{42}$ & 0.1891 & 0.0130 & $(0.1640,0.2150)$ \\
$\gamma_{43}$ & 0.6637 & 0.0087 & $(0.6467,0.6808)$ \\
$\gamma_{52}$ & 0.1784 & 0.0146 & $(0.1502,0.2076)$ \\
$\gamma_{53}$ & 0.6995 & 0.0081 & $(0.6837,0.7152)$ \\
$\gamma_{62}$ & 0.1299 & 0.0095 & $(0.1114,0.1487)$ \\
$\gamma_{63}$ & 0.7007 & 0.0078 & $(0.6852,0.7160)$ \\
$\gamma_{72}$ & 0.1539 & 0.0126 & $(0.1294,0.1791)$ \\
$\gamma_{73}$ & 0.7079 & 0.0078 & $(0.6926,0.7230)$ \\
$\gamma_{82}$ & 0.1915 & 0.0214 & $(0.1500,0.2349)$ \\
$\gamma_{83}$ & 0.6698 & 0.0119 & $(0.6461,0.6930)$ \\
\hline
\end{tabular}

$a$ : 'mean,' 'sd' and '95\% ci' denote the posterior mean, posterior standard deviation and 95\% credible interval, respectively. 
Table 6 (a): Indices of relationships between overall satisfaction and the satisfaction regarding specific aspects of traveling (actual number $)^{a}$

\begin{tabular}{l|cc}
\hline & $\hat{\boldsymbol{\alpha}}_{2}$ & $\boldsymbol{\Sigma}_{(-1)}^{-1} \boldsymbol{\sigma}_{(-1)}$ \\
\hline satfood & 0.1841 & 0.1805 \\
satsouv & 0.1629 & 0.1682 \\
sataccom & 0.1213 & 0.1253 \\
satserv & 0.1123 & 0.1137 \\
sattran & 0.0253 & 0.0340 \\
satequip & 0.0923 & 0.0808 \\
satview & 0.4380 & 0.4279 \\
\hline
\end{tabular}

$a$ : The values are posterior means.

Table 6 (b): Indices of relationships between overall satisfaction and the satisfaction regarding specific aspects of traveling (\%) ${ }^{a}$

\begin{tabular}{l|rr}
\hline & \multicolumn{1}{|c}{$\hat{\boldsymbol{\alpha}}_{2}$} & $\boldsymbol{\Sigma}_{(-1)}^{-1} \boldsymbol{\sigma}_{(-1)}$ \\
\hline satfood & $16.20(2)$ & $15.97(2)$ \\
satsouv & $14.34(3)$ & $14.88(3)$ \\
sataccom & $10.68(4)$ & $11.09(4)$ \\
satserv & $9.88(5)$ & $10.06(5)$ \\
sattran & $2.23(7)$ & $3.01(7)$ \\
satequip & $8.13(6)$ & $7.15(6)$ \\
satview & $38.55(1)$ & $37.86(1)$ \\
\hline
\end{tabular}

$a$ : The values in parenthesis denote descending order. 


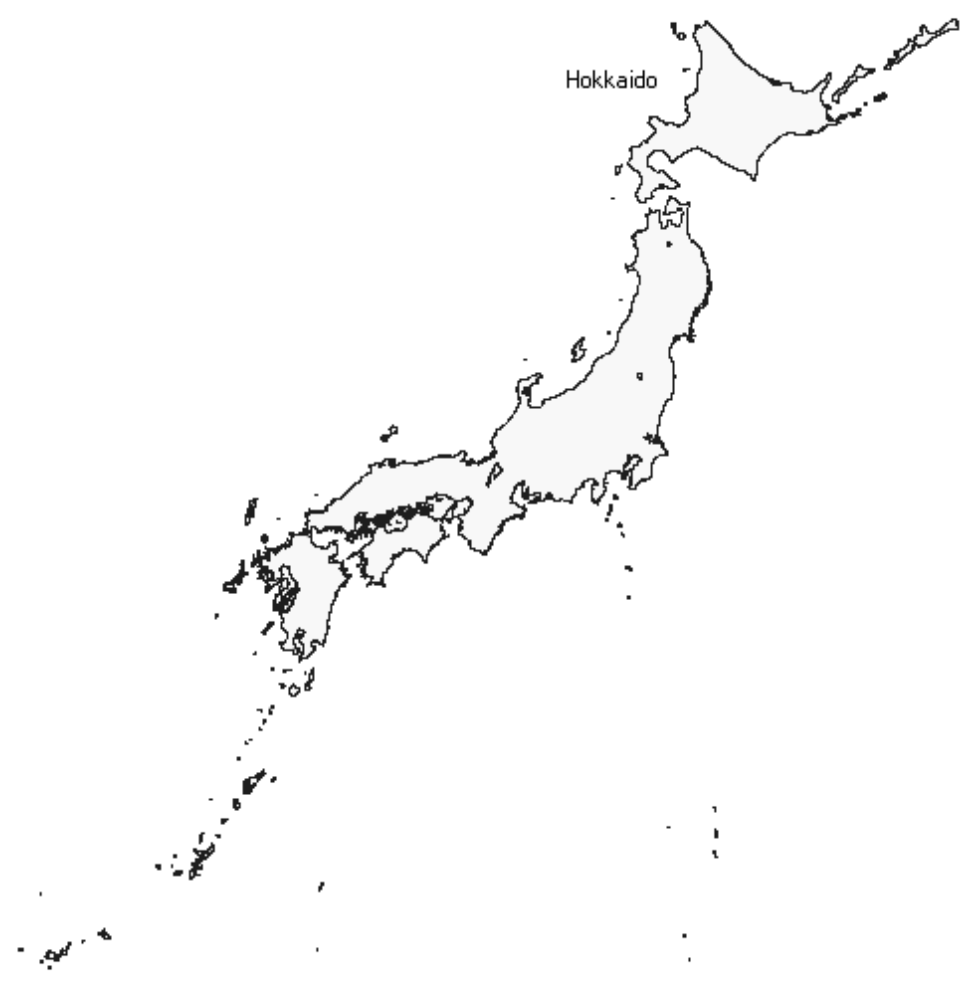

Figure 1: The Map of Japan 


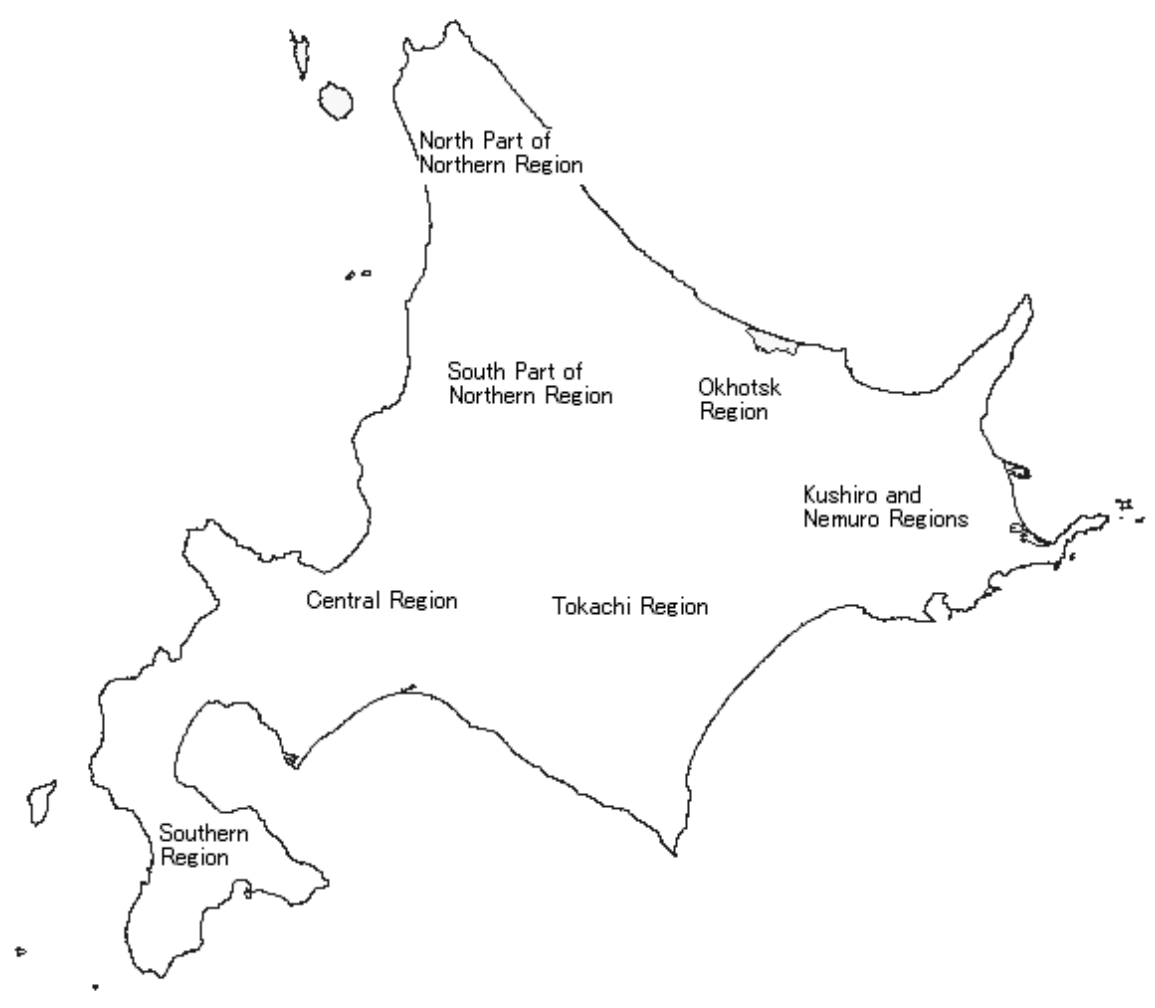

Figure 2: The Map of Hokkaido Prefecture 